\title{
Effects of Exposure in utero to Diesel Exhaust Particles: Mutation Rates in the Developing Male and Female Germline
}

\author{
By \\ Caitlin Ritz
}

\begin{abstract}
A thesis submitted to the Faculty of Graduate and Postdoctoral Affairs in partial fulfillment of the requirements for the degree of
\end{abstract}

\author{
Master of Science \\ in \\ Biology \\ Carleton University \\ Ottawa, Ontario
}

(C) 2011

Caitlin Ritz 
Library and Archives

Canada

Published Heritage Branch

395 Wellington Street Ottawa ON K1A ON4 Canada
Bibliothèque et

Archives Canada

Direction du

Patrimoine de l'édition

395 , rue Wellington

Ottawa ON K1A ON4

Canada
Your file Votre référence

ISBN: 978-0-494-83152-6

Our file Notre référence

ISBN: 978-0-494-83152-6
NOTICE:

The author has granted a nonexclusive license allowing Library and Archives Canada to reproduce, publish, archive, preserve, conserve, communicate to the public by telecommunication or on the Internet, loan, distribute and sell theses worldwide, for commercial or noncommercial purposes, in microform, paper, electronic and/or any other formats.

The author retains copyright ownership and moral rights in this thesis. Neither the thesis nor substantial extracts from it may be printed or otherwise reproduced without the author's permission.
AVIS:

L'auteur a accordé une licence non exclusive permettant à la Bibliothèque et Archives Canada de reproduire, publier, archiver, sauvegarder, conserver, transmettre au public par télécommunication ou par l'Internet, prêter, distribuer et vendre des thèses partout dans le monde, à des fins commerciales ou autres, sur support microforme, papier, électronique et/ou autres formats.

L'auteur conserve la propriété du droit d'auteur et des droits moraux qui protège cette thèse. $\mathrm{Ni}$ la thèse ni des extraits substantiels de celle-ci ne doivent être imprimés ou autrement reproduits sans son autorisation.
In compliance with the Canadian Privacy Act some supporting forms may have been removed from this thesis.

While these forms may be included in the document page count, their removal does not represent any loss of content from the thesis.
Conformément à la loi canadienne sur la protection de la vie privée, quelques formulaires secondaires ont été enlevés de cette thèse.

Bien que ces formulaires aient inclus dans la pagination, il n'y aura aucun contenu manquant. 


\begin{abstract}
:
Previous work has shown that particulate air pollution (PAP) from industrial environments causes DNA mutation in the sperm of adult mice. To investigate the mutagenic effects of PAP on developing gametes, pregnant C57Bl/6 mice were exposed to $19 \mathrm{mg} / \mathrm{m}^{3}$ diesel exhaust particles (DEP) from gestational day 7-19, alongside controls. Mature F1 offspring were mated with control CBA mice. F2 descendents were collected and germline mutation rates were derived for tandem repeat DNA sequences from full pedigrees. No evidence for increased mutation rates was found in females exposed in utero relative to controls. In contrast, a significant increase in mutation frequency for male mice exposed in utero was observed (2-fold; Fisher's Exact $p<0.05$ ). Thus, maternal exposure to DEP results in increased mutation in sperm during development. Single-molecule PCR was used to determine germline mutation rates of $\mathrm{F} 2$ descendents of exposed and control males. We found no evidence for inherited genetic instability in these mice.
\end{abstract}




\section{Acknowledgements}

I would like to thank Wojciech Ruminski, Karin Hougaard, Dr. Vogel, and Dr. Wallin for initiating this project and allowing me to be a part of it. I would also like to thank my committee members for their input and guidance, Dr. Iain Lambert, Dr. Paul White and Dr. William Willmore. A huge thank you goes to Thomas Shipley, Breanne Swayne and Andrea Rowan-Carroll for all of the help and support that they gave during my time as a graduate student. Also to our statistician, Andrew Williams, who conducted all the statistics for this project. I am grateful to my supervisor, Dr.

Carole Yauk, for agreeing to supervise me in the first place and for being patient with my endless questions. Thank you to my friends, family and loved ones who tirelessly supported me through this whole process. Lastly, a special thank you to Matthew Gaudreau who gave me strength and motivation when I really needed it, and my parents, Doug and Carolyn Ritz, who always knew the right way to push me. You are how I made it through. 
Table of Contents

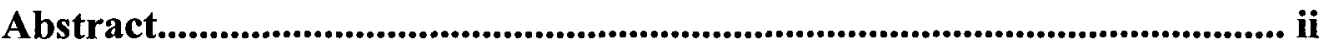

Acknowledgements..................................................................................... iii

Table of Contents........................................................................................ iv

List of Tables..................................................................................................... vi

List of Figures.................................................................................................... vii

List of Acronyms........................................................ viii

Statement of Contribution.................................................................. ix

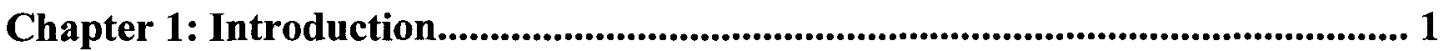

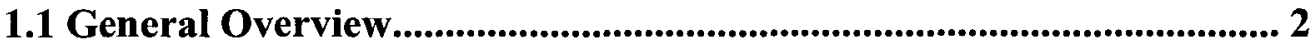

1.2 Germline Mutation Analysis............................................................. 3

1.2.1 Gametogenesis in males and females..................................... 3

1.2.2 Traditional germ cell mutation assays..................................... 8

1.3 ESTRs........................................................................................................ 9

1.4 Effects of Environmental Chemicals on Germline Mutation Using Repeats.................................................... 15

1.5 Transgenerational Genetic instability............................................. 18

1.6 Model Particulate Diesel Exhaust Particles......................................... 20

1.7 Experiment Design.................................................................................... 23

1.8 Objectives and Hypothesis.................................................................... 32

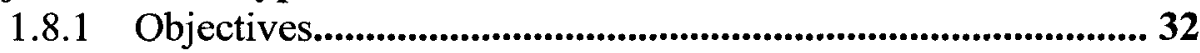

1.8 .2 Hypothesis...................................................................... 32

Chapter 2: Germline Mutation Rates in Mice following in utero Exposure to Diesel Exhaust Particles by Maternal Inhalation.............................. 33

2.1 Introduction.......................................................... 35

2.2 Materials and Methods.............................................. 37

2.2.1 Animal Care.................................................... 37

2.2.2 Extraction of DNA.............................................. 38

2.2.3 ESTR Mutation Analysis....................................... 38

2.3 Results............................................................ 39

2.4 Discussion............................................................... 43

2.5 Conflict of Interest.................................................. 48

2.6 Funding Source.................................................... 48

2.7 Acknowledgements.............................................. 48

Chapter 3: Investigation of Induced and Persistent Genetic Instability in Mice Exposed to Diesel Exhaust Particles in utero.................................... 49

3.1 Introduction....................................................... 50

3.2 Materials and Methods........................................... 55

3.2.1 Animal Care................................................. 55

3.2.2 Extraction and Amplification of DNA..................... 56 
3.2.3 Single Molecule Polymerase Chain Reaction (SM-PCR) analysis........................................................5 57

3.2.4 ESTR Mutation Analysis.................................... 58

3.2.5 Statistical Analysis...........................................59

3.3 Results.............................................................60 60

3.4 Discussion................................................................ 72

3.5 Conclusions and Future Work....................................... 78

3.6 Funding Source...................................................... 80

Chapter 4: Discussion.......................................................... 81

4.1 Previous Experimental Results on the Animals from this Study...... 82

4.2 ESTR Mutation Analysis............................................. 84

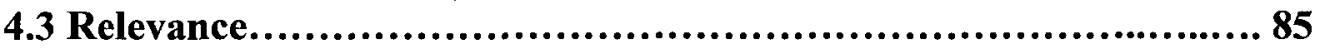

4.4 Future Directions/Recommendations.................................... 89

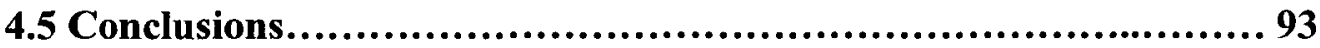

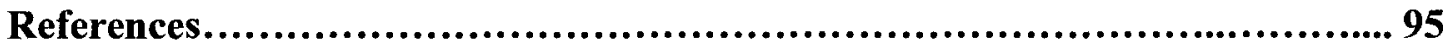




\section{List of Tables}

Table 1-1: Stages of gametogenesis................................................. 6

Table 2-1: Summary of maternal and paternal ESTR mutation frequencies.......... 41

Table 3-1: Mutation frequency of the F1 and F2 generation..........................68

Table 3-2: Mutation analysis of gains and losses................................... 70 


\section{List of Figure Captions}

Figure 1-1: Diagram of an Expanded Simple Tandem Repeat (ESTR) region....... 12

Figure 1-2: Visual representation of the pedigree used in this study................ 25

Figure 1-3: Example of a pedigree analysis gel................................... 27

Figure 1-4: Example of an SM-PCR analysis gel.................................. 30

Figure 2-1: Mutation frequencies with standard errors for males and females exposed in utero to DEP..................................................... 46

Figure 3-1: Mutation frequencies with standard errors for $\mathrm{F} 1$ males exposed in utero to DEP, and F2 male offspring of F1 males exposed in utero to DEP. 63

Figure 3-2: Mutation spectra showing the number of repeat units gained or lost in the $\mathrm{F} 1$ germline analysis and the $\mathrm{F} 2$ germline analysis.................... 65 


\section{List of Acronyms}

DEP: Diesel Exhaust Particle

PAP: Particulate Air Pollution

ESTR: Expanded Simple Tandem Repeat

GD: Gestational Day

PAH: Polycyclic Aromatic Hydrocarbon

ROS: Reactive Oxygen Species

TE: Tris Ethylenediaminetetraacetic acid a.k.a. Tris EDTA 


\section{Statement of Contribution}

Chapter 1: Introduction

Writing of Introduction. Caitlin Ritz

Chapter 2: Germline Mutation Rates in Mice following in utero Exposure to Diesel Exhaust Particles by Maternal Inhalation

Conception. Dr. Carole Yauk, Dr. Ulla Vogel, Dr. Håkan Wallin

Animal Breeding Karin Hougaard, Wojciech Ruminski

Tissue Sampling.......Wojciech Ruminski, Michael Guldbrandsen, Gitte B. Kristiansen DNA Extractions Caitlin Ritz

DNA Digests. Caitlin Ritz

Long Gels. Caitlin Ritz

Southern Hybrydizations and probing Caitlin Ritz Analysis of Results. .Caitlin Ritz, Dr. Carole Yauk, Andrew Williams

Writing of manuscript. Caitlin Ritz

Chapter 3: Investigation of Induced and Persistent Genetic Instability in Mice Exposed to Diesel Exhaust Particles in utero

Conception Dr. Carole Yauk, Dr. Ulla Vogel, Dr. Håkan Wallin

Animal Breeding Karin Hougaard, Wojciech Ruminski

Tissue Sampling. Wojciech Ruminski, Michael Guldbrandsen, Gitte B. Kristiansen DNA Extractions Caitlin Ritz

DNA Digests Caitlin Ritz

SM-PCR reactions. Caitlin Ritz, Thomas Shipley

Short Gels. Caitlin Ritz

Long Gels Caitlin Ritz

Analysis of Results. Caitlin Ritz

Writing of Chapter. Caitlin Ritz, Dr. Carole Yauk, Andrew Williams

Chapter 4: Discussion

Writing of Discussion Caitlin Ritz 
Chapter 1:

\section{Introduction}




\section{Chapter 1: Introduction}

\subsection{General Overview:}

Humans are exposed to chemical toxicants in the air they breathe, the water they drink and the food they eat. Many of the environmental contaminants that have been found in urban air, water and soil are mutagenic (able to cause an alteration in the DNA sequence). Mutations in somatic cells can lead to diseases like cancer, while mutations in germ cells (sperm and egg) can result in transmission of genetic diseases to offspring. Environmental exposures to mixtures of chemicals have been shown to cause germline mutation. For example, breathing ambient air in an industrial urban center (Hamilton, Ontario, Canada) caused a 2-fold increase in germline mutation frequencies in local birds and laboratory mice [1-4]. Currently, a number of toxicants and mixtures, such as radiation, anti-cancer drugs, cigarette smoke and air pollution, have been shown to cause mutation in the germline [3-8]. These studies have been conducted on adult male mice and little is known about increases in mutation in the female germline.

The goal of this thesis was to study the effects of a model particulate air pollutant, diesel exhaust particles (DEPs), on male and female germline mutation following exposure in utero. The experiment was designed to study the mutagenic effects of exposure that arise during both female and male gametogenesis. The study also examined the ability of particulate air pollution (PAPs) to cause transgenerational genetic instability following exposure in utero. The objectives were achieved through the examination of tandemly repeated DNA sequences called Expanded Simple 
Tandem Repeat (ESTR) DNA that have high spontaneous mutation frequencies permitting the direct measurement of spontaneous and induced germline mutations.

\subsection{Germline Mutation Analysis:}

Mutagens that affect the germline are important as they are transmitted to offspring and can persist in future generations. Stable mutations in the germline can cause inherited genetic disease and affect the health of the population. There is currently great controversy over the ability of environmental and medical toxicants to cause germline mutation [9]. However, numerous studies have demonstrated the ability of radiation, PAPs, tobacco smoke and other chemical mutagens to cause germline mutation after parental exposure $[3-6,8,10,11]$. The recent decision by the International Association for Research on Cancer [12] that cigarette smoke causes cancer in unexposed descendents of smokers suggests that support for the notion that environmental chemicals can lead to increased germline mutation is growing [9]. All of the animal studies described above have specifically examined mutations arising in the adult male germline. As a result, information is lacking on the effects caused by maternal exposure, and on potentially sensitive stages of gametogenesis that occur during development.

\subsubsection{Gametogenesis in Males and Females:}

Studies investigating induced mutations have generally used rodent models and have focused on exposure of male animals during different stages of gametogenesis (spermatogenesis). Female gametogenesis (oogenesis) has not been 
studied as extensively. Rodents have been used because they produce many offspring per litter and because there is a high degree of similarity between spermatogenesis in rodents and humans [13]. Males have traditionally been studied over females due to the ease with which spermatogenesis can be studied. Males constantly replenish their germ cells allowing researchers to access large quantities of sperm. Moreover, researchers can target virtually any stage of spermatogenesis, simply by sampling the mature sperm or mating the animals at different time periods post-exposure [13]. Females produce far fewer gametes over their lifetimes than males $(\sim 200,000$ eggs total vs 50-500 million sperm per ejaculate). In addition, females undergo mitotic division, and also begin meiosis I, in utero [13]. Egg cells arrest after completion of the diplotene stage of prophase I, and remain arrested at that stage until sexual maturity [13]. At each estrus cycle, an egg is released in metaphase II, and meiosis II is only completed following fertilization [13]. Thus, the stages of gametogenesis in males and females are spread over much different time scales, which makes it very difficult to study stage specificity in females. In females, exposures must be done in utero during a very short and very distinct time period in order to sample a precise pre-meiotic stage (described below).

By Gestational Day (GD) 8, germ cells are visible in the developing fetus [14]. They enter the gut and migrate into the germinal ridges between GD 9 and 12 [14]. Mitosis occurs during the entire migration process [14]. On approximately GD 11, the sex of the germ cells can be differentiated [14]. Unlike males, females enter Meiosis I before birth [14]. The first stage of prophase I, leptotene, has started by GD 13 [14]. Leptotene and zygotene are completed in the early fetal stages, and 
pachytene, where homologous chromosomes pair up and crossing over occurs, is completed on GD 16-17 [13,14]. Most female germ cells complete the diplotene stage of prophase I just prior to birth, and remain arrested at this stage of development until sexual maturity $[13,14]$. Meiosis I is completed at ovulation, while Meiosis II is only completed upon fertilization $[13,14]$. In contrast to this timeline of events, when the females are entering the leptotene phase of prophase I on GD 13, male germ cells have already differentiated into spermatogonia $[13,14]$. After GD 13, the presence of mitotic germ cells in males are rare [14]. After birth, mitotic divisions that replenish the stock of these cells continues throughout the life of the male [13]. At sexual maturity, two meiotic cell divisions occur to create sperm and following the second division, haploid spermatids can differentiate into fully mature sperm [13]. This is process is repeated for the life of the male [13]. The stage specific differences between males and females are shown in detail in Table 1-1. 
Table 1-1: Stages of gametogenesis in mice. 
Table 1-1: Stages of gametogenesis in mice.

\begin{tabular}{|c|c|c|}
\hline Timeline & Males & Females \\
\hline GD 8 & \multicolumn{2}{|c|}{ Germ cells become visible } \\
\hline GD 9-12 & \multicolumn{2}{|c|}{$\begin{array}{l}\text { Germ cells enter the gut and migrate to the germinal } \\
\text { ridges. Mitosis takes place }\end{array}$} \\
\hline GD 11 & \multicolumn{2}{|c|}{ Sex differentiation } \\
\hline GD 13 & $\begin{array}{l}\text { Have already differentiated } \\
\text { into spermatogonia }\end{array}$ & $\begin{array}{l}\text { Enter first stage of prophase } \\
\text { I, leptotene }\end{array}$ \\
\hline GD 16-17 & Mitotic germ cells are rare & $\begin{array}{c}\text { Pachytene has been reached, } \\
\text { homologous chromosomes } \\
\text { pair and cross-over }\end{array}$ \\
\hline \multicolumn{3}{|l|}{ Birth to sexual maturity: } \\
\hline Birth & $\begin{array}{c}\text { Testis contains } \\
\text { undifferentiated type } A_{1} \\
\text { spermatogonia }\end{array}$ & $\begin{array}{c}\text { Arrested just after diplotene } \\
\text { of prophase I of meiosis I } \\
\text { until ovulation }\end{array}$ \\
\hline Day 3 & $\begin{array}{l}\text { Mitotic differentiation into } \\
\text { advanced spermatogonial } \\
\text { stages }\left(\mathrm{A}_{2}, \mathrm{~A}_{3}, \mathrm{~A}_{4}\right. \\
\text { intermediate and type } \mathrm{B})\end{array}$ & - \\
\hline Day 8-10 & $\begin{array}{l}\text { Spermatocytes are observed } \\
\text { for the first time in the } \\
\text { leptotene phase of meiosis }\end{array}$ & - \\
\hline Day $17-19$ & $\begin{array}{l}\sim 50 \% \text { of the seminiferous } \\
\text { tubules contain cells late in } \\
\text { pachytene stage }\end{array}$ & - \\
\hline Day 20 & $\begin{array}{l}\text { Earliest post-meiotic cells } \\
\text { observed }\end{array}$ & - \\
\hline Ovulation & N/A & Meiosis I completed \\
\hline Fertilization & N/A & Meiosis II completed \\
\hline
\end{tabular}




\subsubsection{Traditional Germ Cell Mutation Assays:}

Germline mutation is extremely difficult to study because spontaneous and induced germline mutations are extremely rare. The spontaneous human germline mutation rate is estimated to be approximately $10^{-8}$ mutations per nucleotide per generation [15]. As a result, traditional methods, such as the Russell Specific Locus Test (SL) or the Dominant Lethal Assay (DL), require both a large number of animals and a large exposure dose in order to observe increased rates of mutation [13].

The SL test was developed in 1951, and is based on the T stock mouse [16]. This mouse is homozygous recessive at 7 specific loci. In this assay, exposed homozygous wild-type mice $(101 \times \mathrm{C} 3 \mathrm{H})$ are mated with unexposed $\mathrm{T}$ stock females (that are homozygous recessive) [16]. Thus, mutation of a dominant gene in the exposed animal to the recessive phenotype leads to expression of the recessive trait. Following parental exposures, offspring are observed for any of the 7 phenotypic characteristics that indicate a mutation has occurred at one or more of these specific alleles [16]. However, the average spontaneous mutation frequency of the SL loci is $6.6 \times 10^{-6}$ per locus per gamete and thus, thousands to tens of thousands of animals must be used in order to observe an effect [13].

The DL assay measures genetic changes in germ cells that cause death of the zygote created from that germ cell either before, at, or after implantation [13]. The lethality comes mainly from structural or numerical errors in chromosomes, such as translocations or aneuploidies [17]. Despite being resource intensive, this assay is still used for regulatory testing of chemicals and/or mutagens. This assay also requires hundreds of animals, is labour and time intensive, and is expensive $[13,18]$. 
The SL and DL assays were developed 40-60 years ago, and as such are no longer used frequently. Thus, although the roots of research on mutation originally focused on germ cells, methodological advances leading to much more rapid assays, such as the Salmonella bacterial mutagenicity assay, have led to insight into somatic mutations and allowed greater emphasis on somatic mutation in toxicology. Because of this, new, highly sensitive assays to measure germline mutation are greatly needed. Within the past 2 decades, a number of groups have begun to focus attention on highly unstable non-coding markers in the genome to study germline mutation. One of these assays, the ESTR assay, is the method used in this thesis and is described in detail below.

\subsection{ESTRs:}

The present work focussed on highly unstable genetic elements in the mouse genome known as Expanded Simple Tandem Repeats (ESTRs). ESTRs are part of a group of tandem repeat DNA. This group also includes microsatellite DNA and minisatellite DNA. Microsatellite DNA sequences are less than $1 \mathrm{~Kb}$ in length (usually $10-100 \mathrm{bp}$ ), and contain repeat units that are 1-5 bp long [19]. All species have microsatellites and a number of important loci are implicated in certain neurological disorders. The rate of microsatellite mutation is high, approximately $10^{-3}$ to $10^{-4}$ per nucleotide per haploid genome. In contrast, minisatellites are up to $20 \mathrm{~Kb}$ in length with repeat units that are 10 to $>50 \mathrm{bp}$ long [19]. Minisatellites are found mostly in non-coding regions of the genome, although associations with disease have been made for a few loci. Minisatellite mutation rate is also high, ranging from $10^{-4}$ to 
0.15 per nucleotide per haploid genome. ESTRs are also found in non-coding regions of the genome, and are not well characterized in humans. They are highly expanded, reaching up to $20 \mathrm{~Kb}$ in length and are composed of short repeat units, approximately 4-10 bp in length [20]. Both microsatellites and ESTRs mutate via a replication based process, whereas minisatellites replicate via a recombination based process. Also, array mutability is associated with the purity of the array for both microsatellites and ESTRs, while minisatellite stability does not appear to be affected by variant repeats, which are scattered throughout minisatellites [21]. Stability of minisatellites seems to be affected by recombination hotspots, which flank the minisatellite region [21].

Work in this thesis was conducted on two ESTRs; the Ms6-hm (HMI) and $H m 2$ loci. $H M 1$ is composed of GGGCA repeat units, repeated up to 400 times ($\left.(\mathrm{GGGCA})_{\mathrm{n}^{-}}, \mathrm{n}>400\right)$ [22]. $\mathrm{Hm} 2$ is composed of GGCA repeat units, repeated up to 5000 times $\left(-(\mathrm{GGCA})_{\mathrm{n}^{-}}, \mathrm{n}>5000\right)$ [23]. ESTRs are highly expanded and can be up to $20 \mathrm{~kb}$ in length [20]. They are found in the non-coding region of the mouse genome. $H M I$ is found near the brown coat locus on the mouse chromosome 4, and $H m 2$ is located on chromosome $9[22,23]$. ESTRs are highly unstable with mutation frequencies between $1 \%$ and $15 \%$ per locus per gamete [7]. ESTRs often form secondary structures like hairpins, Z DNA and other unusual structures, that make it easier to expand or contract their allele size [24]. ESTRs are believed to mutate by a replication-based process, gaining or losing full repeat units as they replicate [25]. ESTR mutations also appear to arise during specific stages of spermatogensis. Evidence suggests that mutations arise exclusively in pre-meiotic, replication and DNA repair-proficient cells [7]. It has been determined that mutations do not occur 
post-meiotically [7]. Thus, exposure of mature females to mutagens would not lead to induced mutation, as female germ cells undergo meiosis in utero. In order to observe induced ESTR mutations, female germ cells would need to be exposed prior to GD 13 , when meiosis begins [26]. 
Figure 1-1: Diagram of an Expanded Simple Tandem Repeat (ESTR) region. Each box represents a repeat unit of $\sim 4-10 \mathrm{bp}$. In the case of $H M l$, indicated here, [$\left.(\text { GGGCA })_{n^{-}}\right], n>400$. These repeat units are repeated in tandem, and can contain as many as 5,000 repeats per locus. ESTRs are highly unstable regions used as biomarkers for genetic instability. Light grey box indicate a repeat unit, dark grey boxes indicate unique sequence DNA. 
Figure 1-1:

$5^{\prime}$ GGGCA GGGCA GGGCA GGGCA $\ldots \ldots$, GGGCA GGGCA Indicates any number of repeats 
Although the exact mechanism of ESTR instability is not well understood, Barber et al. have hypothesized that cell cycle pausing, in response to DNA damage, could increase the number of polymerase slippage events at these repetitive loci, resulting in increased mutation rates [27]. The damage can occur anywhere in the genome; i.e., it does not have to be specific to the ESTR region. This damage causes cell cycle pausing in order to allow for repair prior to replication. If the polymerase is crossing an ESTR at the time of the pause, secondary structures may be formed, and mutations will arise when the polymerase reinitiates extension [27]. Yauk et al. suggest that chemicals or mutagens may modify chromatin conformation (via changes in methylation) and that methylation of DNA may compromise the ability of repair enzymes to access and repair the secondary structures that form across repeated sequences, resulting in increased rates of mutation [28].

ESTRs were first used to study mutagen-induced tandem repeat instability in the germline by Dubrova et al. [10]. These authors demonstrated that rates of germline mutation at tandem repeat sequences in mice responded measurably to ionizing radiation using lower doses and orders of magnitude fewer mice than traditional assays [10]. A high spontaneous mutation frequency was observed at several ESTR loci allowing for statistically significant increases to be observed using smaller sample sizes [10].

There exists some debate as to the relevance of using mouse ESTR mutation frequency as a biomarker of exposure for humans. ESTRs have not been wellcharacterized in the human genome and differ from the minisatellites that have been used for the same purpose in humans. However, ESTRs mutate by a mechanism that 
is very similar to microsatellite DNA. Microsatellites are abundant in the genome of virtually every eukaryotic organism, including humans. A comparison of the dose required to induce a doubling of mutation at ESTR and to cause mutation at other loci reveals a similarity in doubling dose [7]. Thus, there appears to be a correlation between mutation induction at tandem repeats and other loci. There are approximately 20 (and the list is continuing to grow) developmental and degenerative diseases associated with unstable repeat regions [29]. For example, spinal and bulbar muscular dystrophy and fragile $\mathrm{X}$ syndrome are both associated with trinucleotide repeat expansions [29]. These diseases occur due to expansions of non-coding repeats that result in a loss of protein function, or expansions of coding repeats that result in an altered protein function [29]. Recent studies show that expansion of non-coding repeats can also lead to altered RNA function [29]. Thus, it is clear that unstable repeat regions play important roles in some human disorders, and ESTRs may provide valuable insight into our understanding of the potential role of mutagens in the incidence of these disorders.

\subsection{Effects of Environmental Chemicals on Germline Mutation using Repeats:}

Tandem repeat regions have been used to explore the effects of ionizing radiation and chemical mutagens on induced germline mutation in the laboratory $[6,8,10]$. These studies have demonstrated that mutagenic agents with diverse modes of action (e.g., induction of DNA strand breaks, alkylation, topoisomerase inhibition, etc.) cause ESTR mutations. However, exposure to ambient levels of environmental chemicals can also cause repeat mutation. 
Yauk et al. used tandem repeats to study mutations in herring gulls nesting in urban and rural environments [11]. Gulls living in Hamilton Ontario, in close proximity to two operating steel mills and a heavily trafficked highway, passed on twice as many mutations to their offspring as gulls living in a more rural environment. The authors also observed a negative correlation between mutation frequency and nesting distance to the steel mill (i.e., the closer the gulls lived to the steel mill, the higher their mutation frequency). However, the routes and source of exposure were unknown, and there were other confounding effects such as nutritional status and age among the gulls. Contaminants could have been introduced into the gulls via the air, water, or food. Route of exposure is important, especially when trying to determine what the potential negative effects could be on other organisms (e.g., humans) inhabiting that location.

In 2002, a follow-up study was conducted by Somers et al. [3]. In this experiment, laboratory mice were caged in both the urban and rural environments in Hamilton, Ontario. The main difference between the test sites was the air the mice were breathing (i.e., age, husbandry and diet were identical). The mice caged in the urban environment next to the steel mills and the highway passed on two times as many mutations to their offspring as their rural counterparts. Thus, mutation induction was the result of inhalation of contaminated air in the east end of Hamilton. To determine what component of air pollution was responsible for the increase in mutation frequency, Somers et al. then caged mice in the same urban and rural environments as before [4]. However, mice were exposed either to whole air or High Efficiency Particulate Air (HEPA) filtered air [4]. Mice caged in the urban 
environment again had increased mutation frequencies compared to those in rural environments; however, mice caged in urban environments breathing HEPA filtered air displayed a $52 \%$ decrease in mutation frequency, back to those of reference levels. These results demonstrated that the increase in mutation rate could be attributed to the particulate portion of the air, specifically particles $0.3 \mu \mathrm{m}$ or larger, as this is the fraction that HEPA filters remove.

Yauk et al. determined, through the use of Single Molecule Polymerase Chain Reaction (SM-PCR), that mutation was occurring in pre-meiotic spermatogonial cells after exposure to PAP in the Hamilton environment [1]. This same study demonstrated an increase in bulky DNA adducts in the lungs of exposed animals, indicating that they were inhaling Polycyclic Aromatic Hydrocarbons (PAHs). However, no bulky adducts were found in the testes. Thus, high levels of these chemicals do not appear to reach the germ cells. This implies that either PAHs are not the cause of germline mutation or perhaps they act through an indirect mechanism mediated by signals elsewhere in the body [1]. The mice from this experiment exhibited an increase in DNA strand breaks in sperm, possibly implicating an oxidative stress mechanism. Yauk et al. hypothesized that exposure to particles and associated airborne pollutants may result in oxidative stress and influence mutation frequency through this mechanism. Finally, global analysis of DNA methylation revealed a potential role for epigenetics in the mutational mechanism as there was global hypermethylation of sperm DNA after exposure to PAP. Thus, it has been determined that the particulate fraction of the air is responsible for the increase in mutation frequency; however, the mechanism of action is still unclear. 
Increased germline mutation frequencies have been observed after exposure to sources of PAP that are common in the human population, including cigarette smoke

[5]. This indicates that germline mutations are not restricted to a contaminant found in Hamilton, Ontario. Germline mutations likely arise following exposure to mutagens found in most urban centres, and many people are exposed daily. Thus, more work is required to understand the mechanisms leading to germline mutation and the repercussions of changes in tandem repeat sequences.

\subsection{Transgenerational Genetic Instability:}

In addition to mutations in the germline of directly exposed animals, studies have also shown that mutagen exposures can lead to destabilization of ESTRs in the unexposed descendants of exposed males [6,30,31]. Increased mutation rates in the unexposed descendents of exposed animals has been termed 'transgenerational genetic instability', and has been demonstrated to be caused by radiation and ethylnitrosourea (ENU) in adult males [6,8]. For example, a study by Barber et al. revealed that mutation rates at a tandemly repeated DNA locus and a protein coding gene (hprt) were elevated in both the germline and somatic tissue of unexposed descendants of irradiated males [6]. This study used two different strains of mice and results were consistent between the strains. The authors attributed the transgenerational genetic instability to persistent DNA damage, revealed using the comet assay. However, the majority of work in this field is from one laboratory, and more work is required to confirm the findings, explore the exposures that lead to this effect, and determine the mechanism leading to genetic instability. 
There has only been one study, conducted by Barber et al., that investigated the effects of an in utero exposure to mutagens on transgenerational genetic instability [31]. In this study, persistent instability was mediated exclusively through the male germline. The authors hypothesized that the passive erasure of the female epigenetic marks, as opposed to the active erasure of the male epigenetic marks, may lessen the transgenerational effects of in utero exposure. There are two periods of genome-wide DNA methylation reprogramming; once during primordial germ cell differentiation and once during preimplantation development [32]. Within 6 hours of fertilization, the paternally derived DNA is devoid of methylation, however, the process through which this occurs is unknown [32]. In contrast, between the two cell and the morula stage, the maternal DNA demethylates in a slow, replicationdependant process [32]. It is not clear how this could affect transgenerational genetic instability; however, if epigenetics are the cause, then this is a clear difference between the male and female methylation patterns. To date, nothing is known about the ability of particles, especially the ability of particle exposure in utero, to cause transgenerational genetic instability.

The study of inherited transgenerational genetic instability poses a difficult problem for current risk assessment procedures. Traditionally, risk assessment has only taken into consideration effects on the exposed individual or that individual's offspring (i.e., reproductive toxicology). If transgenerational genetic instability is shown to persist after environmental exposures, then risk assessment will have to take into consideration future generations descended from the exposed individual when making their assessment. It is also unclear how long transgenerational genetic 
instability persists. For this reason, more work is required in order to confirm the effects of transgenerational genetic instability and to determine the mechanisms involved in this process.

\subsection{Model Particulate Diesel Exhaust Particles:}

As demonstrated in the experiments described in section 1.4, a major source of exposure to mutagenic agents that affect germ cells is PAP. PAP is the component of air pollution that is made up of particles $0.3 \mu \mathrm{m}$ in size or bigger. Sources include fossil fuel combustion such as engines in a car, power plants, or any industry that requires grinding or crushing, such as quarries, cement, or construction [33]. Thus, DEPs are a contributor to PAP. The particles themselves have the ability to cause damage due to their small size, but the large surface area to volume ratio also allows many chemicals to be adsorbed onto the surface, such as PAHs, transition metals or other mutagens. Air pollution can be measured in many ways, but a filter-based particle/soot absorption photometer (PSAP) is especially good at measuring carbon black, an indicator of many particle pollutions, particularly DEP [34].

As a result of the harmful properties of PAP, many studies have been conducted to determine the effect that exposure may have on human health. These studies indicate that exposure to PAP results in inflammation in the lungs, lung cancer, cardiopulmonary disease and even germline mutations [1,35-38]. Recently, bulky DNA adducts were shown in the placenta of pregnant animals [39]. Carlberg et al. demonstrated that mothers living in urban centres had significantly higher levels of DNA adducts in their placentas than mothers living in rural areas [39]. It is now 
believed that some inhaled chemicals not only reach the placenta, but also the embryo/fetus [40].

DEPs are a component of air pollution that serves as an ideal model for PAP in general. Standard DEP reference materials are available from the National Institute of Standards and Technology, which facilitates acquisition of the particles and improves reproducibility across studies [41]. DEPs are composed mainly of carbon, and are contributors to ambient PAP [37,42]. DEPs are fine particulates, with ninety five percent being less than $110 \mu \mathrm{m}$ in size $[37,42]$. Due to their small size, DEPs have a large surface area to volume ratio and can thus carry chemicals adsorbed on their surfaces [42]. These chemicals include PAHs, nitrated PAHs, aldehydes, quinones, acids and metals such as transition metals [42]. Because these chemicals are adsorbed onto such a small particle, they can be breathed deep into the lung where they can cause damage, possibly via inflammatory responses. Previous studies have indicated that the effects of DEP exposure range from oxidative damage caused by the formation of free-radicals, to bulky DNA adducts and inflammation [37,42-44].

There are many studies that implicate DEPs as mutagenic in different experimental systems. For example, Ye et al. found that both the gaseous and particulate phase of diesel exhaust emissions showed a strong mutagenicity using both the Ames test and a mammalian in vitro micronucleus assay [45]. Muller et al. used the comet assay and $\mathrm{P}^{32}$ post-labelling to demonstrate that DEPs cause DNA strand breaks and bulky DNA adducts [44]. Hashimoto et al. demonstrated that DEPs caused an $\sim 3$ fold increase in mutations in the lungs of gpt delta transgenic mice [46]. They found that GC:AT transitions and GC:TA transversions were both caused after 
DEP exposure. These studies all demonstrate that DEPs are mutagenic in various experimental systems.

The first way in which DEPs are believed to cause damage after inhalation is through the formation of bulky DNA adducts that can lead to mutations [47]. Studies have indicated that ingestion of PAP causes bulky DNA adducts not only in the gastro-intestinal tract, but in the lungs as well, indicating that PAHs have the ability to affect non-target organs [44]. However, a study by Yauk et al. demonstrated that inhaled PAP resulted in bulky DNA adduct formation in the lungs, but not in the testis, where germline mutation had previously been observed [1]. These results suggest that the damage caused by inhalation of DEP was caused indirectly by PAHs, or by another mechanism or chemical component of air particulates (e.g., metals) entirely.

Inhalation of small particles, even those composed of pure carbon, has been shown to cause pulmonary inflammation [48]. Thus, it is possible that inhalation of DEP itself, regardless of what is adsorbed onto it, may cause inflammation and the production of Reactive Oxygen Species (ROS). Transition metals adsorbed onto the surface of DEP may exacerbate this process via the production of more ROS through the Fenton reaction [1]. In 2003, Risom et al. demonstrated that exposure to DEP caused cellular oxidative stress that ultimately results in DNA damage [42]. They studied oxidative stress by examining 8-oxo-7,8-dihydro-2'-deoxyguanosine (8oxodG) and found that multiple small doses of DEP may upregulate the antioxidative defense system (OGG1), whereas one large dose resulted in an increase in 8-oxodG in lungs [42]. This indicates that DEP causes oxidative stress, but that small, chronic 
doses may not pose as much of a threat as large doses, due to our body's ability to defend against this type of injury.

\subsection{Experiment Design:}

The present research uses DEP as a model particulate air pollutant to study mutations arising in the developing germline. The work specifically quantifies ESTR mutation frequency in exposed and control animals. ESTRs have traditionally been studied in two ways: Pedigree analysis or SM-PCR analysis. A pedigree analysis involves taking DNA from somatic tissues of parents, and comparing it to that of the somatic DNA of the offspring, in order to identify size differences in the offspring relative to their parents (Figure 1-2 and 1-3). For example, F1 males would be exposed, either as adults or in utero, mated with control females and offspring collected. DNA from spleen of parents and offspring (F1 parents and F2 pups) would be isolated and studied by Southern blot analysis (Figure 1-3). Mutations are measured as any offspring band that differs from the parental band by more than $1 \mathrm{~mm}$. Parent of origin is determined by the proximity of the mutation to the original parent band, male or female. Mutation frequency is calculated as the number of mutant bands, divided by the total number of bands scored. The drawback of this method is the number of animals required for the analysis ( $\sim 200$ in total for a single dose and control), the length of time required, and the cost. It is also difficult using the pedigree analysis to discern somatic mosaic mutations (a mutation resulting from a mutation early in embryogenesis and seen as a similar sized mutant in multiple 
offspring) from individual de novo germline mutations. This will be discussed further in the chapter on SM-PCR analysis. 
Figure 1-2: Visual representation of the pedigree used in this study. Pregnant C57B1/6 mice were exposed to DEP from gestational day 7-13. This produced the F1 generation, which had been exposed in utero. The F1 generation was allowed to grow to maturity and mated with unexposed $\mathrm{CBA} / \mathrm{J}$ mates to produce the $\mathrm{F} 2$ generation. Circles represent females; squares represent males, grey shading indicates exposure to either DEP or sham controls. 
Figure 1-2:

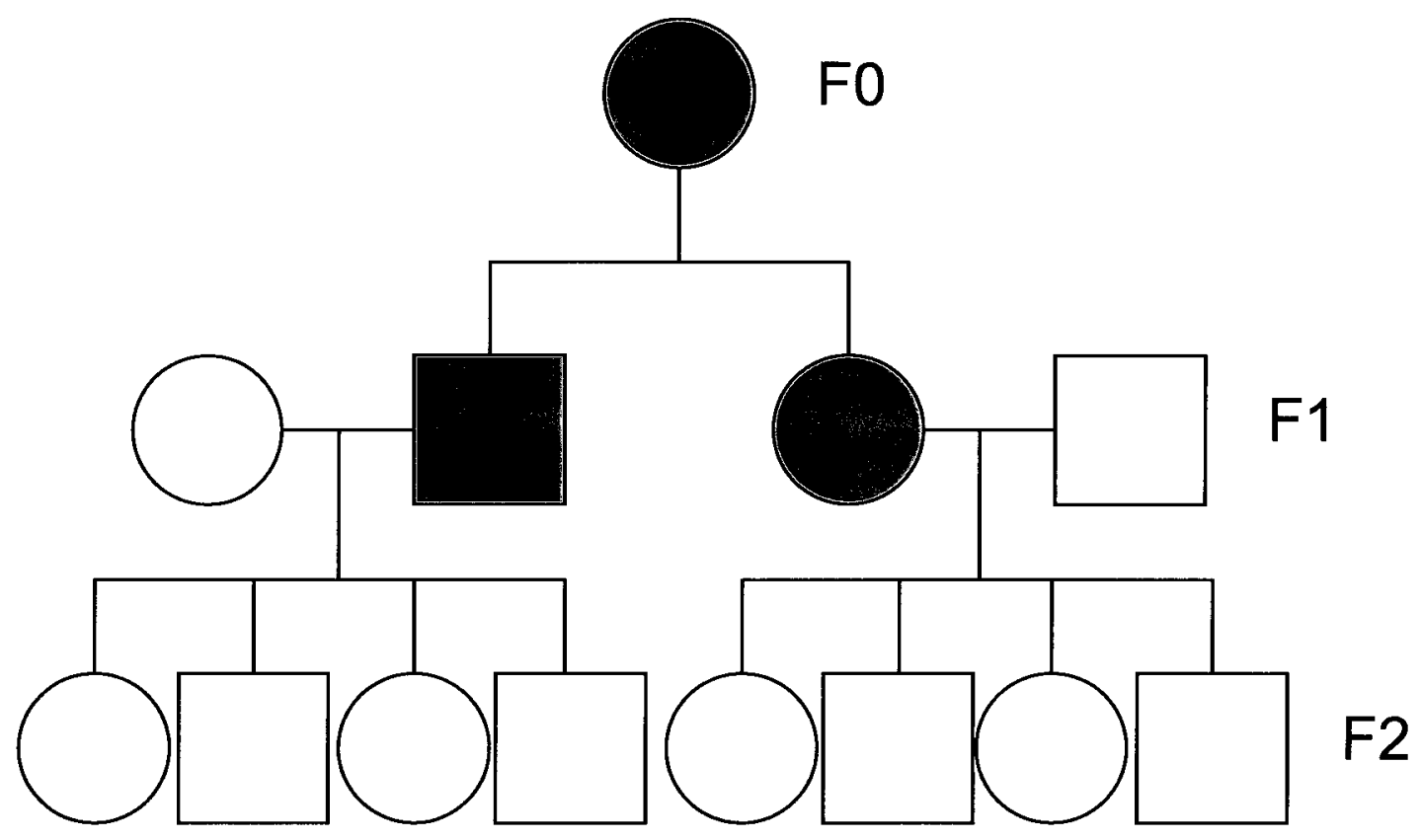


Figure 1-3: Example of a pedigree analysis gel. Paternal and offspring DNA are labelled. DNA fragments in the offspring should migrate at the same rate as the parental DNA. DNA that is a different size in the offspring, resulting from a gain or loss of repeat units, is clearly observed as a size shift in the offspring relative to the parental allele. A mutation is shown with a red arrow. 
Figure 1-3:

$1 \mathrm{~kb}$ ladder

Paternal

Orifspring

DNA

DNA

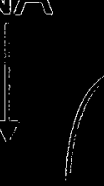


The advent of SM-PCR has allowed the study of mutation induction using sample sizes that are orders of magnitude lower than traditional assays, and with doses that are more environmentally relevant [9]. The use of SM-PCR allows the analysis of single molecules of sperm DNA directly; thus, every molecule can be considered as a potential offspring. In the pedigree analysis, male parents are exposed, mated, and their offspring are used for analysis, as described above. Using SM-PCR, males are exposed and the sperm DNA studied to quantify germline mutation. Sperm DNA is isolated, restriction enzyme digested and diluted down to concentrations of one single molecule per reaction well. The ESTR locus of interest is PCR amplified and the size of each allele is analyzed using agarose gel

electrophoresis. Gels are Southern blotted onto nylon membranes and probed with $\mathrm{P}^{32}$ labelled probe, specific for the ESTR of interest (Figure 1-4). SM-PCR allows for the detection of mutation in both the germline and somatic tissue of the same animal, allowing a direct comparison between somatic and germline effects. A drawback of this analysis is the inability to analyse large alleles reliably, or at all, because of PCR limitations. 
Figure 1-4: Example of an SM-PCR analysis gel. Amplified sperm DNA and reference ladders are labelled. PCR amplified $H M I$ alleles should migrate at the same rate as each other. Alleles that are a different size in an individual sperm cell, resulting from a gain or loss of repeat units, is observed as a size shift in the band relative to the average allele size (progenitor). A mutation is shown with a red arrow. 
Figure 1-4:

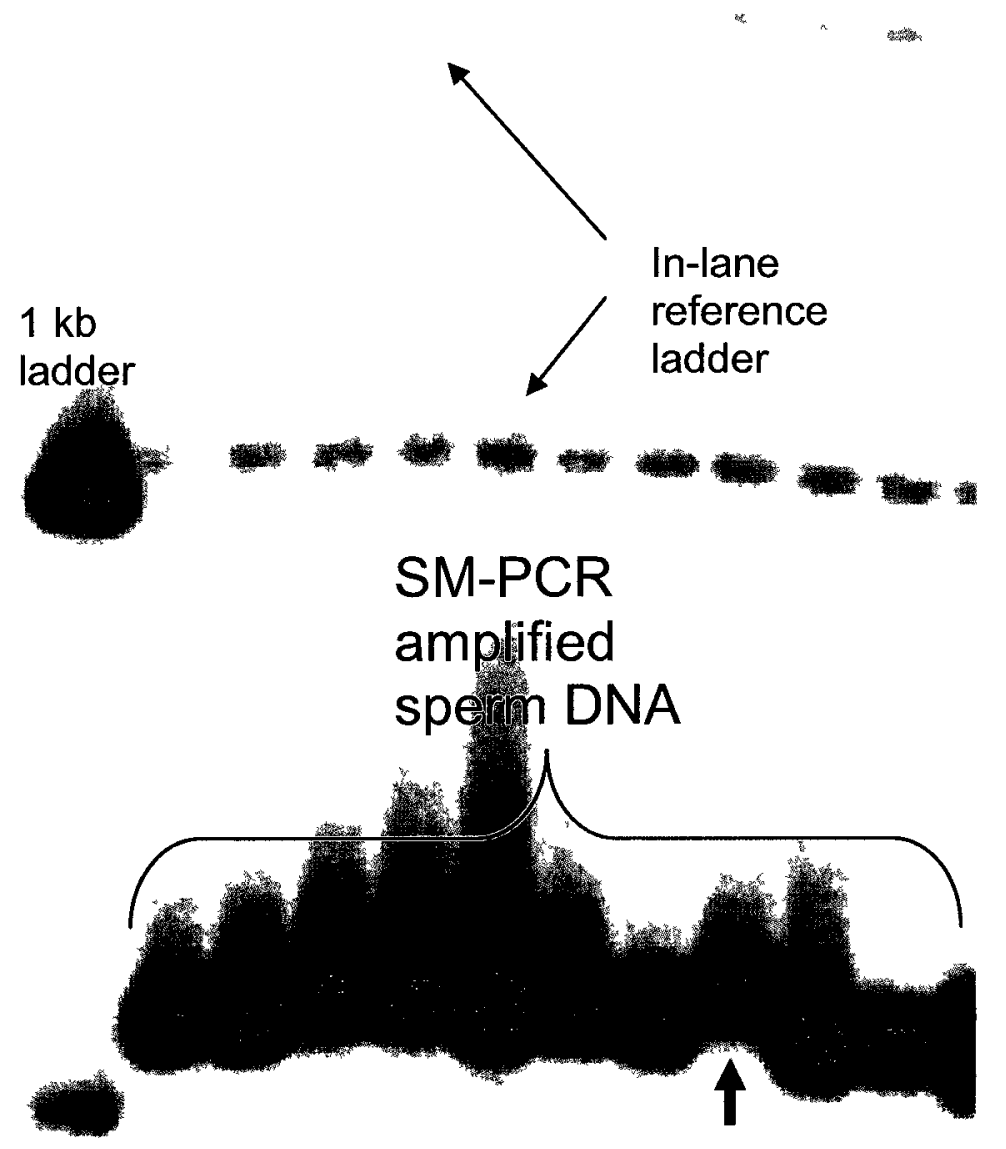


This thesis examines the effect of DEP (as a model particulate air pollutant) on the developing germline, in both male and female mice, using a pedigree analysis of highly unstable tandem repeats in DNA. In addition, this work also examines the potential for particles to cause transgenerational increases in genetic instability. The work was carried out in an effort to observe the effects of breathing DEP on the developing germline, and also to gain insight into the effects on the developing female germline.

\subsection{Objectives and Hypothesis:}

\subsubsection{Objectives:}

The objective of this research is to examine ESTR mutation frequency in the germline of male and female mice exposed to DEP in utero and their unexposed descendents, alongside matched controls in order to:

1. Determine whether germline mutations result following in utero exposure to DEP.

2. Compare and contrast mutations arising in the male and female germline.

3. Determine whether transgenerational effects arise following DEP exposure.

\subsubsection{Hypothesis:}

1. Inhaled DEP will result in germline mutation at ESTR loci in mice exposed during gametogenesis.

2. Exposure to DEPs in utero will result in transgenerational genetic instability. 


\section{Chapter 2:}

\section{Germline Mutation Rates in Mice following in utero Exposure to Diesel Exhaust Particles by Maternal Inhalation}

This manuscript was published in Mutation Research:

Ritz, C; Ruminski, W., Hougaard, K.S., Wallin, H., Vogel, U., Yauk, C.L. (2011). Germline Mutation Rates in Mice Following in utero Exposure to Diesel Exhaust Particles by Maternal Inhalation. Mutation Research - Fundamental and Molecular Mechanisms of Mutagenesis 712 (1-2) 55-58 DOI: 10.1016/j.mrfmmm.2011.04.007

Mutation Research is published by Elsevier. The publication policy for this journal states that the 'author retains the right to include the article, in full or in part, in a thesis or dissertation'. 


\section{Chapter 2: Germline Mutation Rates in Mice following in utero Exposure to}

\section{Diesel Exhaust Particles by Maternal Inhalation}

\section{Authors:}

Caitlin Ritz ${ }^{1,}$, Wojciech Ruminski ${ }^{2,}{ }^{*}$, Karin S Hougaard ${ }^{2}$, Håkan Wallin ${ }^{2,3}$, Ulla $\operatorname{Vogel}^{2,4,5}$, Carole L. Yauk ${ }^{1, \S}$,

${ }^{1}$ Environmental Health Science and Research Bureau, Health Canada, Ottawa, Ontario, K1A 0K9, Canada

${ }^{2}$ National Research Centre for the Working Environment, Copenhagen, Denmark

${ }^{3}$ Institute of Public Health, University of Copenhagen

${ }^{4}$ Institute for Science, Systems and Models, Roskilde University, Roskilde

${ }^{5}$ National Food Institute, Technical University of Denmark, Soborg, Denmark

* These authors contributed equally to this manuscript.

${ }^{\S}$ Corresponding Author: Carole Yauk, Health Canada, Tunney's Pasture, Bldg. 8 (P/L 0803A), 50 Columbine Driveway, Ottawa, Ontario K1A 0K9 Canada,

Tel: 613-957-3141-7376; Fax: 613-941-8530 


\subsection{Introduction:}

Over the past decade, research has shown that particulate air pollution (PAP) can lead to detrimental effects in germ cells of exposed humans and mice $[1,38]$. Maintaining the stability of the germline genome is of critical importance because germline mutations can be transmitted to the offspring through the egg or sperm, potentially leading to increased genetic disease and/or related fitness in the next generation.

Previous work has examined the effects of PAP-contaminated air on germline mutation through the analysis of instability at tandem repeat DNA sequences. Expanded Simple Tandem Repeats (ESTRs) are composed of short sequences ( 4-10 base pairs long) that are tandemly repeated. These loci are prone to mutation by expansion or contraction [25]. In situ exposure studies conducted near two integrated steel mills in Hamilton, Ontario, have repeatedly demonstrated the effects of PAP on inherited ESTR mutations in laboratory mice $[1,3,4,11]$. For example, the offspring of laboratory mice caged in an area located near the steel mills exhibit a 1.5-2-fold increase in the number of inherited mutations over the offspring of mice held at rural sites [3], or mice breathing air with particles removed by High Efficiency Particle Air (HEPA) filtration [4]. A subsequent study demonstrated a 1.6-fold higher mutation rate in the sperm of mice exposed to whole air relative to HEPA-filtered air [1]. This study also established that although there were no stable bulky DNA adducts in the sperm of mice exposed to PAP, there were increases DNA strand breaks and global DNA methylation in sperm [1]. Increased strand breaks may result from reactive 
oxygen species (ROS) elicited in response to particulate exposure and/or metals in the air [1].

Various chemicals in PAP are known to reach the placenta, and numerous effects have been observed in animals exposed in utero [1,39]. For instance, Carlberg et al. [39] showed that mothers living in an urban center had significantly higher levels of DNA adducts in their placentas than mothers living in rural locations. It has now been established that some inhaled environmental chemicals reach the placenta, as well as the embryo/fetus $[39,40]$. In addition to a lack of understanding of mutation induction during gametogenesis in general, little is known about potential effects of PAPs on female germline DNA stability. A recent study by Barber et al. demonstrated that induced ESTR mutation rates were similarly elevated in males and females after in utero exposure to ionizing radiation in both germline and somatic cells [31]. Moreover, the authors found that paternal in utero irradiation resulted in transgenerational instability in the exposed mice's offspring, in both somatic and germline cells, but females exposed in utero did not transmit transgenerational genetic instability to their descendents [31]. In the present study we use a similar experimental design to investigate the ESTR mutation frequencies of male and female mice exposed to PAPs in utero.

Our model for PAP in the present study is Diesel Exhaust Particles (DEPs). DEPs, a component of PAP, cause oxidative damage, DNA adducts and increased DNA strand breaks $[42,43,49-52]$. Inhalation of DEP has been shown to cause inflammation in the lungs of mice, however, exposure is not limited to the pulmonary system $[52,53]$. The mucociliary clearance system removes a large fraction of the 
particles from the lungs and transports them to the oral cavity, where particles may be ingested [53]. Polycyclic Aromatic Hydrocarbons (PAHs) may then enter into the circulation causing DNA damage in distal organs [44]. Indeed, PAH adducts are detected in lungs following oral exposure to DEP. In the present study, mice were exposed in utero to DEP via inhalation, and mated with control mice at maturity in order to score germline mutations in offspring.

\subsection{Materials and Methods:}

\subsubsection{Animal Care:}

Animals were bred and exposed at the National Danish Research Centre for the Working Environment in Copenhagen, as described in Hougaard et al. [35]. Briefly, pregnant C57Bl/6 mice were exposed to $19 \mathrm{mg} / \mathrm{m}^{3}$ DEP (NIST 2975 standard reference material from the exhaust of an industrial forklift) from gestational day 7-19 for $1 \mathrm{hr} /$ day, alongside mice exposed to air. These females gave birth to the F1 generation, of which a maximum of one male and female were weaned at postnatal day 22. Three days after weaning, differential cell count analysis was performed on bronchoalveolar lavage fluid from exposed dams to assess lung inflammation, as described in Saber et al. 2005 [51]. At 19 weeks of age the F1 offspring were crossmated with 12 week old unexposed $\mathrm{CBA} / \mathrm{J}$ mates, producing the $\mathrm{F} 2$ generation, resulting in a total of 39 breeding pairs producing offspring for this study (C57B1 F1 Controls: 10 males and 10 females; C57B1 F1 DEP: 10 males and 9 females). For the first F2-litter, time-to-delivery, litter size, offspring weight gain during lactation and gender ratio were recorded. 
Tissue was obtained from F2 pups shortly after birth (sacrificed by decapitation), or on PND 23 or 24, and from F1 parents upon termination of breeding (older pups and F1 parents were anaesthetized then sacrificed by exsanguination). Spleen and tail were flash frozen in cryotubes (NUNC) in liquid $\mathrm{N}_{2}$. All samples were stored at $-80^{\circ} \mathrm{C}$ until use. All procedures complied with EC Directive 86/609/EEC and Danish laws regulating experiments on animals (permit 2006/5611123).

\subsubsection{Extraction of DNA:}

DNA was isolated from the spleen of the F1 parents and the F2 pups using a previously described genomic DNA isolation method [54]. Briefly, samples of spleen were digested in 5M NaCl, $2 \mathrm{M}$ Tris- $\mathrm{HCl} \mathrm{pH} 8,0.5 \mathrm{M}$ EDTA pH 8, 10\% SDS with $0.3 \mathrm{mg} / \mathrm{ml}$ Proteinase $\mathrm{K}$ (Invitrogen, Burlington, Ont) overnight at $55^{\circ} \mathrm{C}$. Tissue lysates were purified using phenol:chloroform and chloroform. The DNA was ethanol precipitated and resuspended in 1x Tris Ethylenediaminetetraacetic acid (TE). Concentrations and quality were determined by UV spectrophotometry using a Thermo Scientific NanoDrop 1000 analyzer (Ottawa, Ont).

\subsubsection{ESTR Mutation Analysis:}

ESTR mutation analysis was conducted as described in Dubrova et al. [7]. Twelve micrograms of DNA was digested with AluI (New England BioLabs, Pickering, Ont.) overnight at $37^{\circ} \mathrm{C}$. DNA from full pedigrees of mice (father, mother and offspring) was electrophoresed on $40 \mathrm{~cm}$ long, $0.8 \%$ agarose gels (Seakem LE) 
alongside a $1 \mathrm{~Kb}$ internal marker (Invitrogen, Burlington, Ont). Gels were run for 48 hrs at $130 \mathrm{~V}$ in cooled chambers until fragments $<1 \mathrm{~Kb}$ were off the gel. DNA was transferred to a nylon membrane (GE Osmonics, Minnetonka, MN) by Southern blotting. All blots were probed with $\alpha^{32} \mathrm{P}$ radiolabeled $M s 6-h m$ probe, stripped and reprobed with $\alpha^{32} \mathrm{P}$ radiolabeled $H m 2$ probe [7]. Gels were visualized using a phosphoimager (Typhoon Trio + Variable Mode Imager from GE Healthcare Biosciences, Piscataway, NJ). The $M s 6-h m$ and $H m 2$ alleles were scored relative to the DNA standard ladder and classified as mutants if the band migration was $1 \mathrm{~mm}$ further or less than the migration of the parental progenitors. Mutant alleles were identified by two separate observers who were blinded to the exposure information during scoring. Mutation rates were calculated as the number of mutant bands divided by the total number of bands scored, and compared using a one-tailed Fisher's exact probability test.

\subsection{Results:}

In the parental generation, pregnant mice were exposed to $19.1+/-1.13 \mathrm{mg} / \mathrm{m}^{3}$ $\operatorname{DEP}\left(\sim 1 \times 10^{6}\right.$ particles $/ \mathrm{cm}^{3}$; mass median diameter congruent with $\left.240 \mathrm{~nm}\right)$ on gestational days 7-19, for $1 \mathrm{hr} /$ day (refer to [35] for details). Dams displayed no clinical signs of adverse effects, and no statistically significant differences were observed in the cellular profile in bronchoalveolar lavage fluid from exposed and control dams, shortly after weaning. Litter size and sex ratios of F1 litters were similar in exposed and control groups [35]. However, F1 DEP exposed pups exhibited significantly lower body weights at the end of the lactation period and reduced growth 
rates relative to control pups during lactation [35]. F1 mice were mated with unexposed mates to produce the F2 progeny. No statistically significant differences owing to prenatal exposure were observed for litter size, offspring weight during lactation, or gender ratios. Time-to-delivery of the first F2 litter was similar for breeding pairs of control females versus females exposed in utero to DEP. The median number of days was 23 for controls (range 21-25 days) and 23 days for females exposed to DEP in utero (range 21-24 days). For males, time-to-delivery was somewhat right skewed, but this was not statistically significant (Kruskal-Wallis, $p=$ 0.352). Time-to-delivery for control males was 24.5 days (range 21-25) and 27 days for DEP exposed males (range 22-73).

Exposure of male mice in utero for 13 days resulted in a significant 2 fold increase in paternal mutation frequency $(p=0.047)$ (increased number of size shifts in the paternal allele inherited by pups relative to father) (Table 2-1). The same exposure of male mice in utero resulted in a marginally significant increase in mutation of the unexposed maternal allele ( 2 fold increase, $p=0.074)$ (Table 2-1); this result may have failed to achieve statistical significance because of the slightly smaller sample size for this group.

In contrast to the exposed males, the exposure of female mice in utero to DEP did not lead to an increase in mutation rate (Table 2-1). Although there was an apparent non-significant 2-fold increase in the maternal mutation frequency $(p=$ 0.1588 ), the controls from this group had a very low mutation frequency. Indeed, the exposed female mutation rate is similar to that of the control male mutation rate, suggesting there is no effect. 
Table 2-1. Summary of maternal and paternal ESTR mutation frequencies. 
Table 2-1. Summary of maternal and paternal ESTR mutation frequencies.

\begin{tabular}{|c|c|c|c|c|c|c|c|c|c|c|c|}
\hline & $\begin{array}{l}\# \\
\text { Offspring }\end{array}$ & $\begin{array}{l}\# \\
\text { Paternal } \\
\text { Mutations }\end{array}$ & $\begin{array}{l}\# \\
\text { Maternal } \\
\text { Mutations }\end{array}$ & $\begin{array}{l}\text { Male } \\
\text { Mutation } \\
\text { Rate } \\
\end{array}$ & $\begin{array}{l}\text { Standard } \\
\text { Error }\end{array}$ & $\begin{array}{l}\text { Female } \\
\text { Mutation } \\
\text { Rate } \\
\end{array}$ & $\begin{array}{l}\text { Standard } \\
\text { Error }\end{array}$ & $\begin{array}{l}\text { Fold } \\
\text { Change } \\
\text { Male }^{\mathrm{a}} \\
\end{array}$ & $p$-value ${ }^{b}$ & $\begin{array}{l}\text { Fold } \\
\text { Change } \\
\text { Female }^{a} \\
\end{array}$ & $p$-value \\
\hline $\begin{array}{l}\text { DEP } \\
\text { Males }\end{array}$ & & & & & & & & & & & \\
\hline $\begin{array}{l}\text { Control } \\
\text { Males }\end{array}$ & 88 & 11 & 9 & 0.063 & 0.026 & 0.051 & 0.024 & & & & \\
\hline $\begin{array}{l}\text { Exposed } \\
\text { Males }\end{array}$ & 64 & 16 & 13 & 0.125 & 0.041 & 0.102 & 0.038 & $\begin{array}{l}2.00 \\
(0.68 \\
4.03)\end{array}$ & 0.047 & $\begin{array}{l}1.99 \\
(0.55 \\
4.28)\end{array}$ & 0.074 \\
\hline $\begin{array}{l}\text { DEP } \\
\text { Females }\end{array}$ & & & & & & & & & & & \\
\hline $\begin{array}{l}\text { Control } \\
\text { Females }\end{array}$ & 79 & 9 & 5 & 0.057 & 0.026 & 0.032 & 0.020 & & & & \\
\hline $\begin{array}{l}\text { Exposed } \\
\text { Females }\end{array}$ & 72 & 5 & 9 & 0.035 & 0.022 & 0.063 & 0.029 & $\begin{array}{l}0.610 \\
(0.0756, \\
1.6019)\end{array}$ & 0.261 & $\begin{array}{l}1.98 \\
(0.2450 \\
5.1903) \\
\end{array}$ & 0.159 \\
\hline
\end{tabular}

${ }^{a}(95 \%$ confidence interval)

${ }^{\mathrm{b}}$ Fisher's Exact 1-tailed p-value 


\subsection{Discussion:}

In the present study, we analysed tandem repeat sequences in full pedigrees (F1 parents alongside F2 pups) to determine germline mutation frequencies in the F1 male and female mice exposed in utero to DEP relative to control mice. We found a statistically significant increase in the germline mutation rate of males exposed in utero to DEP, but no effect on female germline mutation rates (Figure 2-1; Table 21).

The 2-fold increase in paternal mutation frequency indicates that repeated daily exposures in utero to DEP, which forms a complex constituent of urban air pollution, results in increased germline mutation rates in exposed males. The work is consistent with previous findings on the ability of other combustion-derived particulates (e.g., cigarette smoke [5] and urban air pollution $[1,3,4]$ ) to cause germline mutations in adult male mice. However, we now demonstrate that the effects of particulate air pollutants on germline DNA extend to the exposed developing fetus. This finding is also consistent with previous work by Barber et al. examining the effect of in utero radiation exposure (1 Gy on gestational day 12) in mice on germline tandem repeat mutations [31]. In that study, in utero exposure of male mice increased ESTR mutation 2.3 fold at the $M s 6-h m$ and $H m 2$ loci [31]. Therefore, our in utero exposure to DEP elicited effects similar to that of 1 Gy acute gamma radiation.

The marginally significant increase at the maternal allele after paternal exposure in utero is an interesting result as it suggests a non-targeted effect of male exposure on the female allele. Destabilization of the maternal allele following a male exposure has previously been observed for tandem repeats. Niwa et al. showed a 
statistically significant increase in mutation rate at the maternal allele after male parents were mated with unexposed females immediately following irradiation [55]. The authors hypothesized that DNA damage in irradiated sperm caused genomic instability in the zygote that led to mutation in the paternally derived allele in cis and the maternally derived allele in trans [55]. In contrast, in our study, mice were exposed in utero, grown to maturity and then mated (Table 2-1). Thus, DNA adducts and other lesions should no longer persist in the adult male mice. Our results are more in line with the phenomenon of persistent genetic instability. ESTR mutations are known to arise by an indirect mechanism of mutation associated with DNA replication $[25,56]$ and exposure of male mice to chemicals and radiation lead to transgenerational mutations for ESTR loci [8,31]. Moreover, the offspring of male mice exposed to radiation in utero (i.e., the unexposed descendents) exhibit transgenerational genetic instability, in the form of increased germline and somatic ESTR mutation frequencies [31]. As such, persistent genetic instability in the embryo/fetus may explain the non-targeted mutation, and non-targeted mutation of the female allele in the present study may result from an epigenetic mechanism $[1,28]$. This hypothesis is supported by the observation of changes in global methylation in the sperm of mature male mice following exposure to urban air particulate pollution [1], and changes in DNA methyltransferases and global methylation in chemicals that also lead to ESTR mutation [28]. Thus, the results suggest that the genetic instability observed following exposure to radiation may also extend to particulate air pollutants. More research is needed to investigate this hypothesis. 
In contrast to our lack of result after female exposure in utero, Barber et al. observed a 2-fold induction of germline mutation rates following in utero exposure of female mice to 1 Gy of acute radiation [31]. The authors targeted gestational day 12; on this day female germ cells are actively undergoing mitotic proliferation until they are arrested at approximately day 13.5 in mice [57]. Thus, it is possible that there was insufficient cumulative exposure to DEP prior to mitotic/meiotic arrest to cause an increase in the female mutation rate. Moreover, the sample size from the present study is relatively small, and more work will be needed to definitively determine if there is an effect of in utero exposure to DEP on female germline mutation. This work should include higher doses at earlier gestational time points and a larger sample size.

The results of this study demonstrate that particulate air pollutant exposure in utero increases male germline mutation frequency. The work suggests that some portion of the chemicals, or reactive metabolites of DEP, cross the placenta to affect the developing fetus. Yauk et al. [1] proposed that the mutagenic effects of PAPs may be the result of metals or involve generation of reactive oxygen species. However, at the current time, it is unclear if it is damage to cells by chemicals or their metabolic products $[58,59]$, or an epigenetic signal, that leads to mutation in the paternal and maternal alleles in the offspring of exposed males. 
Figure 2-1: Mutation frequencies with standard errors for males (1a) and females (1b) exposed in utero to DEP. ${ }^{*} p<0.05$. The difference between maternal sham and DEP mutation rates in exposed males (1a) was marginally significant $(p=0.074)$. 


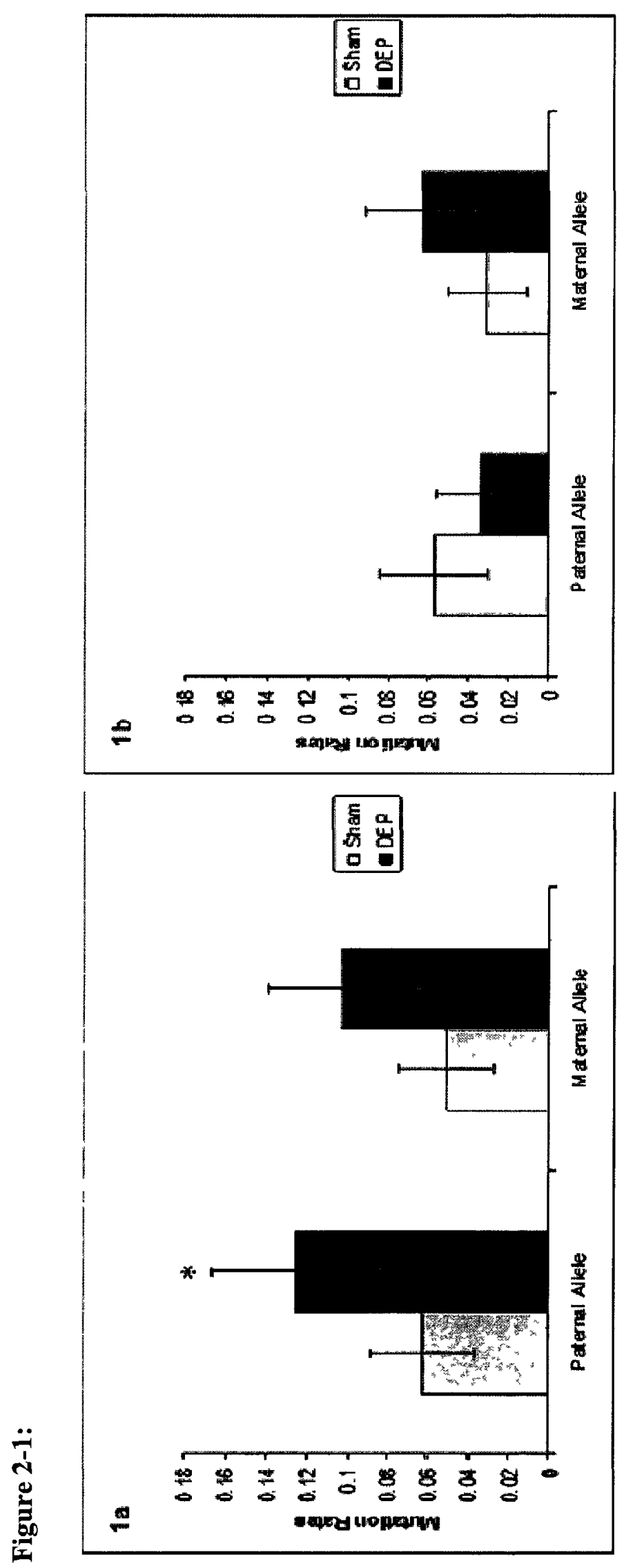




\subsection{Conflict of Interest:}

None.

\subsection{Funding Source:}

This research was supported by grants from the Canadian Regulatory Systems for Biotechnology, Health Canada A-base funding and the Danish Research Council (grant 2052-03-0016), Air pollution in a life time health perspective (Airpolife). Salary support for C.R. was provided by the Natural Sciences and Engineering Research Council of Canada.

\subsection{Acknowledgements:}

We thank Michael Guldbrandsen and Gitte B. Christiansen for care and monitoring of the animals. We acknowledge Lourdes Peterson for skilled lab instruction, and Pernille Nordly for assessing cell composition in BAL fluid. We thank George Douglas and Paul White for helpful comments on the manuscript. 


\section{Chapter 3:}

Investigation of Induced and Persistent Genetic Instability in Mice Exposed to Diesel Exhaust Particles in utero 


\section{Chapter 3: Investigation of Induced and Persistent Genetic Instability in Mice}

\section{Exposed to Diesel Exhaust Particles in utero}

\subsection{Introduction:}

Particulate Air Pollution (PAP) has been shown to be related to many health issues and is a problem in most urban centers. The World Health Organization (WHO) recently listed PAP as the most harmful component of the global air pollution problem today [37]. The general population is exposed to PAP on a daily basis, and this continuous exposure has now been linked to many health problems including lower birth weights, cardiovascular and lung disease $[35,36]$.

One component of PAP that may contribute to the observed health effects is Diesel Exhaust Particles (DEPs). DEPs are a common component of PAP in most urban centres, along with other suspended particulate matter from cars, power plants and boilers [33]. Studies have shown that exposure to DEPs is correlated with various adverse health effects [35-37].

Various studies have demonstrated that DEPs are mutagenic in vitro and in vivo. For example, Jacobson et al. confirmed the mutagenic effect of DEPs in vitro using FE1-Muta ${ }^{\mathrm{TM}}$ Mouse lung epithelial cells [43]. A significantly elevated mutant frequency $(1.99$-fold, $p<0.001)$ was found following treatment of FE1 cells with 75 $\mu \mathrm{g} / \mathrm{ml} \mathrm{DEPs} \mathrm{[43].} \mathrm{Salvi} \mathrm{et} \mathrm{al.} \mathrm{examined} \mathrm{the} \mathrm{effects} \mathrm{of} \mathrm{DEPs} \mathrm{on} \mathrm{the} \mathrm{airways} \mathrm{of} \mathrm{healthy}$ human volunteers [37]. After exposing volunteers to dilute DEPs for 1 hour daily (during light exercise), lung function, bronchoscopy and blood tests were performed [37]. No change in lung function was observed, however, there was an increase in immune response cells and a resulting inflammatory response in both the systemic 
and pulmonary systems [37]. DEP inhalation also causes oxidative DNA damage in mice in vivo [42], and ingestion results in bulky DNA adducts in the gastro-intestinal tract and lungs [44]. Increased inflammation, oxidative DNA damage and bulky DNA adducts can all lead to an increase in mutation frequency.

One mechanism by which DEPs are thought to act to cause mutagenicity is via the generation of Reactive Oxygen Species (ROS) that induce cellular oxidative stress. Risom et al. studied oxidative stress by examining 8-oxo-7,8-dihydro-2'deoxyguanosine (8-oxodG) [42]. As discussed in section 1.6, they found that a single high dose of DEPs generate oxidative damage in lung tissue, whereas the same dose spread over 4 days (i.e., a lower daily dose that amounts to the acute dose) may upregulate the antioxidative defence system (OGG1) and protect against the generation of oxidative damage [42]. DEPs are also associated with various mutagenic/carcinogenic compounds that are adhered to its surface such as Polycyclic Aromatic Hydrocarbons (PAHs) or nitrated PAHs. These chemicals, or their metabolites, can interact with DNA to form bulky DNA adducts [60]. Muller et al. established that ingested DEP results in PAH adducts in the gastro-intestinal tract, as well as other tissues, such as lungs [44]. This indicates that PAHs from DEPs can circulate and affect untargeted organs. However, as mentioned in section 1.6, Yauk et al. demonstrated that mice exposed to PAP in an industrial urban environment exhibited bulky DNA adducts in their lungs, but not in their testes, despite seeing an increase in germline mutation frequency at tandem repeat loci [1]. This indicates that the animals were exposed to PAHs but that these PAHs did not reach the testis. Thus, 
Yauk et al. speculated that an alternative mechanism, such as oxidative stress, played a more important role than expected in the increased mutation rates observed [1].

We previously demonstrated that exposure of pregnant dams to DEPs via inhalation led to a 2-fold, statistically significant, increase in inherited tandem repeat mutation frequencies in their offspring ([61]; see Chapter 2). This is consistent with previous findings on the ability of PAP to cause germline mutations [1-4]. For example, as previously discussed in section 1.4, Yauk et al. demonstrated a 2-fold increase in mutation frequency in herring gulls living in an urban centre, compared with gulls living in a more rural environment [2]. There was also a negative correlation between mutation frequency and nesting distance to an operating steel mill; the closer the gulls nested to the steel mill, the higher their mutation frequency. Somers et al. determined that laboratory mice caged in the same urban and rural locations as the Yauk et al. study also had a 2-fold increase in mutation frequency [3]. In this study, the main variable was the air that the mice were breathing [3]. Mice breathing HEPA filtered air also showed a 52\% decrease in mutation frequency, back to those of reference levels, indicating that it is the particulate portion of the air pollution that is causing the increase in mutation frequency [4]. Thus, strong evidence suggests that diverse particulate air pollutants can impact the germline and cause increased transmission of mutations to offspring of exposed animals.

The literature reviewed above pertains primarily to studies conducted on adult animals. Very few studies have examined germline mutations arising in animals exposed in utero to mutagenic agents. In 2009, Barber et al. revealed a 2.3-fold increase in paternal mutation frequency after exposure of males to $1 \mathrm{~Gy}$ of radiation 
on gestational day 12 (GD 12) [31]. A comparison of these data with our previous work [61] suggests that a DEP exposure of $19 \mathrm{mg} / \mathrm{m}^{3}$ over 13 days had a similar induction potential as 1 Gy acute radiation. This previous work (see Chapter 2) also demonstrated a 2-fold, marginally significant increase in the maternally derived allele after males were exposed in utero [61]. These findings were similar to those of Niwa et al. who detected a significant increase in mutation rate for the maternal allele after male parents were irradiated and mated immediately post-irradiation [55]. Niwa et al. hypothesized that DNA damage in the irradiated sperm caused genomic instability in the zygote [55]. The DEP exposed mice were not mated immediately post-exposure (they were mated at maturity, while exposure stopped at birth), thus, DNA adducts and other lesions should no longer have been present at the time of mating. This suggests a potential role for persistent genetic instability in the increased maternal allele mutation rate.

Genetic instability occurs when the genome has an increased tendency to acquire mutations. Genetic instability is deemed persistent if it persists past the duration of the event causing the instability. For instance, exposure to a chemical may result in genetic instability, however, if the instability persists, even after the exposure is no longer present, then it is described as persistent genetic instability. Persistent genetic instability is important because it means that chemicals/mutagens can have an effect, even long after the exposure is finished. Parental exposure can result in increased mutation frequencies in the germline that can be detected in the offspring [62]. However, when genomic instability occurs in the offspring of exposed parents, it is termed transgenerational genetic instability [62]. 
Barber et al. not only demonstrated that $1 \mathrm{~Gy}$ of radiation on GD 12 produced an approximate 2 -fold increase in mutation frequency in both male and female offspring (as described above), but also a transgenerational effect [31]. Sperm sampled from males exposed in utero had a 2.4-fold increase in mutation frequency compared to unexposed controls [31]. However, sperm sampled from the male offspring of these males exposed in utero also had a 2.5-fold increase in mutation frequency compared to controls [31]. This indicates a persistent genetic instability in the germline that is passed through the sperm to subsequent generations. Although females exposed in utero exhibited an increased germline mutation frequency, there was no evidence for genetic instability in their unexposed descendents [31]. Thus, exposure to mutagens in utero appears to lead to transmission of genetic instability, though this only appears to be mediated through the male lineage.

The present study was undertaken to investigate the effects of in utero exposure to DEPs on the developing germline in mice, as a model for human exposure. The germline is important to consider as mutations that effect the germline can be passed on to future generations, ultimately affecting the health of the population. Tissues used in this study were obtained from a behavioural study conducted by Hougaard et al. [35]. Pregnant mice were exposed to $19 \mathrm{mg} / \mathrm{m}^{3}$ DEP for 1 hour a day from gestational day (GD) 7 to 19 [35]. Mice that were exposed in utero were grown to maturity and mated with control mates to produce the F2 generation [35]. Sperm from the exposed F1 and unexposed F2 were examined using Single Molecule Polymerase Chain Reaction (SM-PCR). 


\subsection{Materials and Methods:}

\subsubsection{Animal Care:}

The animals for this study were bred, cared for and exposed at the National Danish Research Centre for the Working Environment in Copenhagen, as described in Hougaard et al. [35]. Time-mated pregnant C57Bl/6 mice were supplied by Taconic Europe (Ejby, Denmark) on GD 3 [35]. The mice were housed with bedding and enrichment in controlled environmental conditions (12 hr light-dark cycles starting at 6:00 a.m., $21+/-2^{\circ} \mathrm{C}$, humidity $50+/-5 \%$, ventilation 13 air changes per hour) [35]. Mice were given food and water ad libitum [35]. The day after arrival, mice were divided into 2 groups with similar body weights [35]. The mice were exposed to Diesel Exhaust Particles (DEPs) using NIST 2975, a standard reference material from the exhaust of an industrial forklift (Gaithersburg, MD, USA) [35].

Dams were exposed to $19 \mathrm{mg} / \mathrm{m}^{3}$ via inhalation, from gestational day $7-19$, for 1 hour/day [35]. The specific surface area of the particles was $90 \mathrm{mg}^{2} / \mathrm{g}$ reported by NIST and confirmed by multipoint nitrogen adsorption (Micromeritics, Gemini 2375) [35]. Control mice were placed in the inhalation apparatus but were exposed to ambient air inside the facility [35]. Exposure was performed in $18 \mathrm{~L}$ inhalation chambers [35]. Airflow in the chamber was $20 \mathrm{~L} / \mathrm{min}$ and evenly distributed [35]. Dispersion nozzles were used to aerosolize the particles at a pressure of 5 bar (Frauenhofer Institute Fur Toxicologie und Aerosolforschung, Germany) [35]. These mice produced the F1 generation that were exposed in utero. 
F1 mice were born and raised to 19 weeks of age. F1 mice were then mated with 12 week old unexposed $\mathrm{CBA} / \mathrm{J}$ mates to produce the $\mathrm{F} 2$ generation [35]. One male mouse was placed with one female for breeding [35].

After it was confirmed that females produced a litter, the F1 generation was anaesthetized with a mixture of $1.5 \mathrm{mg} / \mathrm{kg}$ hypnorm and $1.5 \mathrm{mg} / \mathrm{kg}$ dormico and sacrificed by exsanguination [35]. The F2 pups were sacrificed 3 weeks after birth by decapitation [35]. Tissues were collected from both the F1 and F2 generations at the time of sacrifice. Testis, caudal and caput epididymus and vas deferens were flash frozen in cryotubes (NUNC) in liquid nitrogen and stored at $-80^{\circ} \mathrm{C}$ until required [35]. The entire animal care and collection process complied with European Council (EC) directive 86/609/EEC and Danish laws regulating experiments on animals (permit 2006/561-1123).

\subsubsection{Extraction and Amplification of DNA:}

DNA for this experiment was isolated using a genomic DNA isolation method, previously described by Yauk et al. [54]. Briefly, the caudal epididymus was used to isolate mature sperm. Tissue was chopped up to liberate mature sperm into a Petri dish. Samples were suspended in Phosphate Buffered Saline (PBS) to release sperm from tubules. A differential lysis was conducted using 10\% Sodium Dodecyl Sulfate (SDS) to enrich for sperm followed by incubation with $0.2 \times$ SSC, Betamercaptoethanol, $10 \%$ SDS, EDTA and Proteinase $\mathrm{K}$ at $37^{\circ} \mathrm{C}$ overnight. DNA was purified using a phenol:chloroform isolation and ethanol precipitation [26]. Finally, the DNA was resuspended in filter sterilized water. A quality check was performed 
using UV spectrophotometry and concentrations were determined using a Thermo Scientific NanoDrop 1000 analyzer (Thermo Scientific, Ottawa, Ont.). Samples were not used unless the absorbance ratio fell within 1.7-2. All isolations were conducted in a laminar flow hood to prevent the risk of sample contamination. Ten $\mu \mathrm{g}$ of DNA was digested per sample using $M s e I\left(10 \mathrm{U}\right.$ at $37^{\circ} \mathrm{C}$ overnight).

\subsubsection{Single Molecule Polymerase Chain Reaction (SM-PCR) analysis:}

SM-PCR analysis was performed as described in Yauk et al. [54] with some modifications. Briefly, template DNA was diluted down to concentrations that would allow for $35-65 \%$ of the reactions to produce observable products, a positive reaction. Generally, this was around 5-15 pg of DNA per well. The Ms6-hm (HMI) locus (5.1 $\mathrm{kb}$ in $\mathrm{F} 1$ generation, 5.1 and $1.7 \mathrm{~kb}$ in $\mathrm{F} 2$ generation) was amplified using $0.5 \mu \mathrm{M}$ flanking primers $H M 1$-for (5'-AGA GTT TCT AGT TGC TGT GA-3') and $H M 1$-rev (5'-GAG AGT CAG TTC TAA GGC-3') in PCR buffer from Roche Expand Long Template PCR System (Roche, Laval, Quebec, Canada \# 11759060 001) for F1 generation or Roche High Fidelity PCR System dNTPack (Roche \# 04738276 001) for F2 generation. Amplifications were conducted using the following conditions: $94^{\circ} \mathrm{C}$ for 2 minutes, followed by 28 cycles of $94^{\circ} \mathrm{C}$ for 20 seconds, $57^{\circ} \mathrm{C}$ for 30 seconds, $68^{\circ} \mathrm{C}$ for 8 minutes and a final extension of 10 minutes at $68^{\circ} \mathrm{C}$. Reactions were $10 \mu 1$ and performed in 96-well skirted plates with caps in PTC-225 DNA Engine Tetrad Thermocycler unit (MJ research now BioRad).

A range of DNA concentrations were examined in pilot PCRs for each sample to determine the concentration of DNA that would yield a $35-65 \%$ positive reaction 
frequency. DNA was diluted to $10,25,50$ and $100 \mathrm{pg} / \mu 1$. Dilutions were made in $5 \mathrm{mM}$ Tris and $5 \mathrm{ng} / \mu \mathrm{l}$ Herring Sperm DNA. Products were run on a $0.8 \%$ agarose gel $(10 \mathrm{~cm})$ to determine the ratio of positive to negative (i.e., blank) reactions. A full 96well plate was then run at a concentration that should yield approximately $50 \%$ positive reactions. All products from the plate were electrophoresed on a $0.8 \%$ agarose gel $(10 \mathrm{~cm})$ to identify the wells in the 96 well plate containing product. Finally, PCR products were run on a $0.8 \%$ agarose long gel $(40 \mathrm{~cm})$ in darkened, air conditioned chambers. Each chamber contained 1 xTBE buffer and was run at $130 \mathrm{~V}$ for approximately 48 hours, until the $1 \mathrm{~kb}$ ladder marker was at the end of the gel.

All gels were Southern blotted onto nylon membranes and probed using an $H M 1$ specific $\mathrm{P}^{32}$ radiolabelled probe for visualization using a phosphoimager (Typhoon Trio + Variable Mode Imager from GE Healthcare Biosciences). Probes were made using a Rediprime II labelling kit and a ProbeQuant G-50 microcolumns clean-up kit from Amersham Biosciences (Baie d'Urfe, Quecbec, Canada \#RPN1633, \#27-5335-01).

\subsubsection{ESTR Mutation Analysis:}

All gels were scored blindly with respect to treatment group. The $H M I$ bands were scored relative to a standard in-lane ladder and were classified as mutations if a band was shifted by more than $1 \mathrm{~mm}$ from the progenitor allele size. Mutants were scored by 2 separate observers to confirm mutant designation. Multiple mutations that were the same size within an animal were considered a somatic mosaic mutation and 
scored as one singleton mutation. Only unique mutant bands were considered unique mutations.

\subsubsection{Statistical Analysis:}

Most statistical procedures used were taken from Yauk et al [54] and are described in Sokal and Rohlf [63]. The 95\% confidence intervals used to determine the number of progenitor molecules and the mutation frequency were derived from the Poisson Distribution [64]. The probability that $x$ molecules will be in the $X_{j}^{\text {th }}$ well is given by the Poisson equation:

$$
P\left(X_{j}=x\right)=\frac{e^{-\lambda} \lambda^{x}}{x !}, \text { for } x=0,1, \ldots
$$

However, when calculating the probability of observing product, a frequentists approach must be used, as only the presence or absence of product can be observed. The probability of observing no product was calculated based on the proportion of wells with no product $\left(p_{0}\right)$. The rate parameter for a single well was calculated:

$$
\begin{aligned}
P(X=0) & =p_{0} \\
e^{-\hat{\lambda}} & =p_{0} \\
\hat{\lambda} & =-\log \left(p_{0}\right)
\end{aligned}
$$

The expected number of progenitor molecules was calculated by multiplying the rate parameter for a single well by the total number of wells. The confidence intervals were then calculated using a Poisson regression model for repeated measures. 


\subsection{Results:}

Pregnant F0 dams were exposed to $19.1+/-1.13 \mathrm{mg} / \mathrm{m}^{3}$ DEPs $\left(\sim 1 \times 10^{6}\right.$ particles $/ \mathrm{cm}^{3}$; mass median diameter congruent with $240 \mathrm{~nm}$ ) via inhalation, from GD 7-19, for $1 \mathrm{hr} /$ day [35]. NIST 2975 has been analyzed for chemical composition, and there are 11 NIST certified PAHs present [41]. These include phenanthrene, fluoroanthene, pyrene, benzo[a]anthracene, chrysene, triphenylene, benzo[j]fluoranthene, benzo $[k]$ fluoranthene, benzo $[e]$ pyrene, benzo $[a]$ pyrene and benzo[ghi]perylene [41]. There are also 28 reference PAHs and 17 reference nitrosubstituted PAHs associated with NIST 2975 [41]. Reference values are non-NISTcertified, best guess analysis of the material [41]. For more information on NIST 2975, please refer to the National Institute of Standards and Technology Certificate of Analysis for SRM2975 [41].

The effects of the DEP exposures on the dams, and some effects on the F1 and F2 generation were published previously by Hougaard et al. [35]. Briefly, there were no significant differences in phenotype or pulmonary inflammation between the dams in the two treatment groups [35]. The only significant difference was in body weights of the F1 offspring. Although the F1 generation had similar litter sizes and sex ratios between treatment groups, the DEP exposed group weighed less at the time of birth, and this difference increased during lactation $(p<0.05)$ [35]. The F2 generation did not show the same differences. Litter size, offspring weight, and gender ratios were all the same between treatment groups in the F2 [35].

SM-PCR analysis of the F1 C57B1/6 allele showed no increase in mutation frequency after DEP exposure in utero (Fig 3-1), based on an analysis of 
approximately 365 molecules. The $\mathrm{C} 57 \mathrm{Bl} / 6$ allele was approximately $5.1 \mathrm{~kb}$ when the $285 \mathrm{bp}$ from the primers were included, which made it very difficult to amplify. The average allele size without the base pairs from the primers was $4.9 \mathrm{~kb}$, ranging between 4.4 and $5.0 \mathrm{~kb}$. Because the PCR conditions were on the borderline of optimization, the reactions were not consistent. Despite multiple attempts to troubleshoot the reaction, the C57Bl/6 allele would not amplify reliably. Exacerbating this problem, only 4 control mice and 3 exposed mice of the 10 control and 9 exposed samples were amplifiable. The control group had a mutation frequency of 0.0342 $(0.0267,0.044)$ and the exposed group had a mutation frequency of $0.0384(0.0294$, 0.049) $(p=0.7)$ (Table 3-1). Thus, the exposed group had a mutation frequency that was 1.12 fold above the control group. This increase was not statistically significant. A total of approximately 735 sperm molecules were scored in the F2 male descendents of the F1 males. Analysis was conducted only on the smaller F2 CBA/J maternal allele, as this small allele was preferentially amplified over the long $5.1 \mathrm{~kb}$ allele. The $\mathrm{CBA} / \mathrm{J}$ allele size was approximately $1.7 \mathrm{~kb}$ when the $285 \mathrm{bp}$ from the primers were included. The average allele size (repeats only) was $1.3 \mathrm{~kb}$, and ranged from 1.1 to $1.8 \mathrm{~kb}$. As a result, the short CBA allele was always preferentially amplified over the long $\mathrm{C} 57 \mathrm{Bl} / 6$ allele. This amplification problem is routinely encountered with PCR on alleles of widely differing sizes [54]. This analysis revealed no increase in mutation frequency after in utero DEP exposure of the F1 males (Fig 31b). The control group had a mutation frequency of $0.0436(0.0357,0.0559)$ and the exposed group had a mutation frequency of $0.0407(0.0326,0.052)(p=0.6872)$ 
(Table 3-1). Thus, there were no significant differences in the germline mutation frequencies of male descendents of control or DEP-exposed males.

Mutation spectrum analysis (i.e., frequency distribution of insertion and deletion mutations) was conducted on the F1 and F2 mice (Figure 3-2a and b). These figures show the progenitor allele sizes as well as those outside the progenitor range (mutants). The overall distribution is a normal distribution. There was no apparent propensity to gain or lose repeat units in the F1 generation (Fig 3-2a) or the F2 generation, although there were slightly more losses ( $\sim 6-10$ repeat units) than gains in the F2 (Fig 3-2b) generation. There were no differences in mutation spectrum between the control and the exposed groups (Fig 3-2). 
Figure 3-1: Mutation frequencies with standard errors for F1 (a) males exposed in utero to DEP, and F2 (b) male offspring of F1 males exposed in utero to DEP. The $5.1 \mathrm{~kb} \mathrm{C} 57 \mathrm{Bl} / 6$ allele from exposed $\mathrm{C} 57 \mathrm{Bl} / 6$ males crossed with control CBA/J females was scored in the $\mathrm{F} 1$ generation, and the $\mathrm{CBA} / \mathrm{J}$ maternal allele was scored in the F2 generation. 


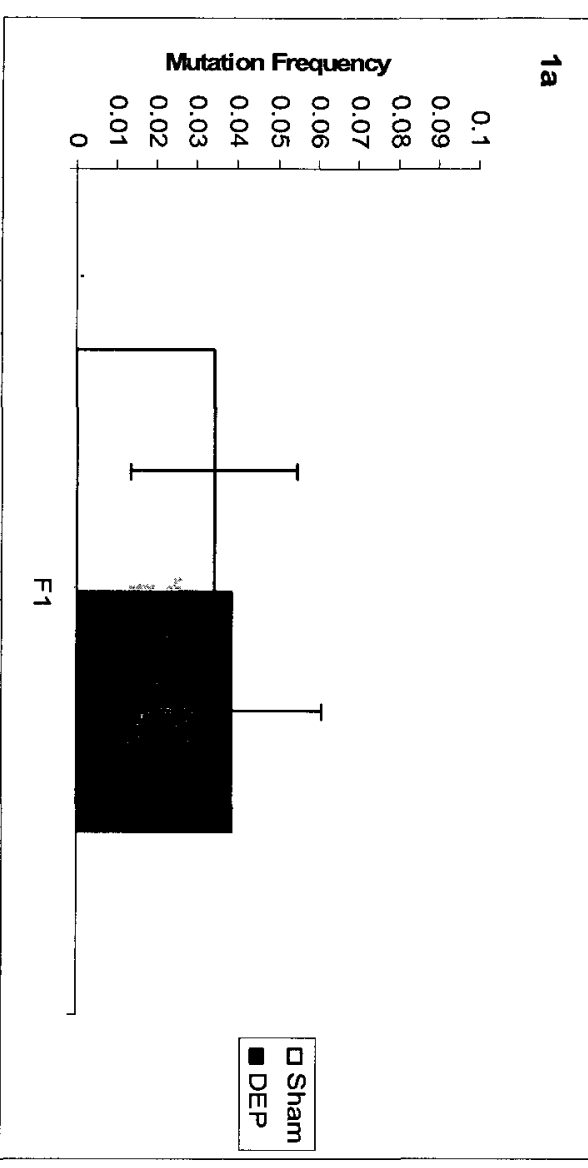

骂

Mutation Frequency

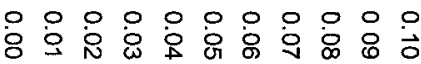

$\vec{\sigma}$

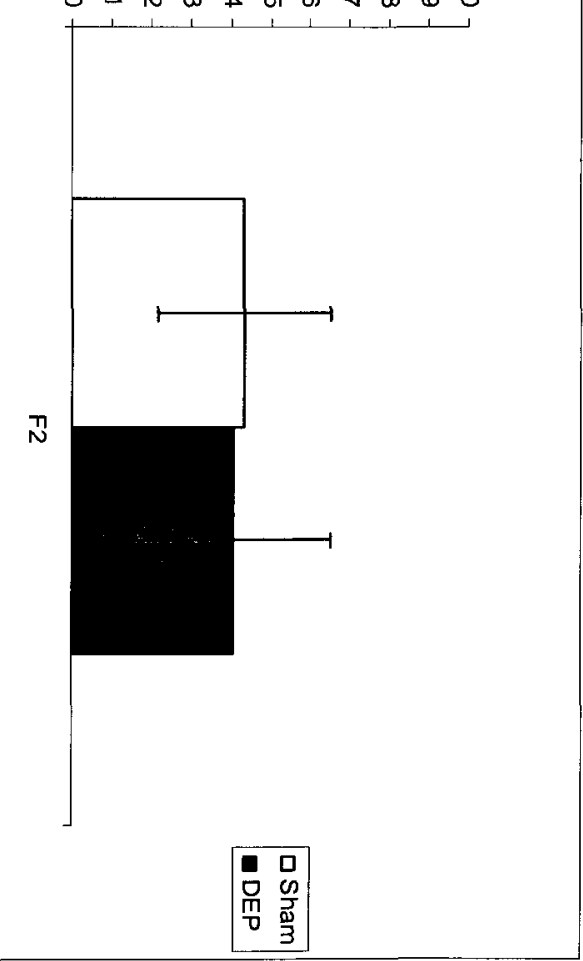


Figure 3-2: Mutation spectra showing the number of repeat units gained or lost in the $\mathrm{F} 1$ germline analysis (a) and the F2 germline analysis (b). Average allele size (progenitor) is indicated by the red box ( $+/-4$ repeat units). 


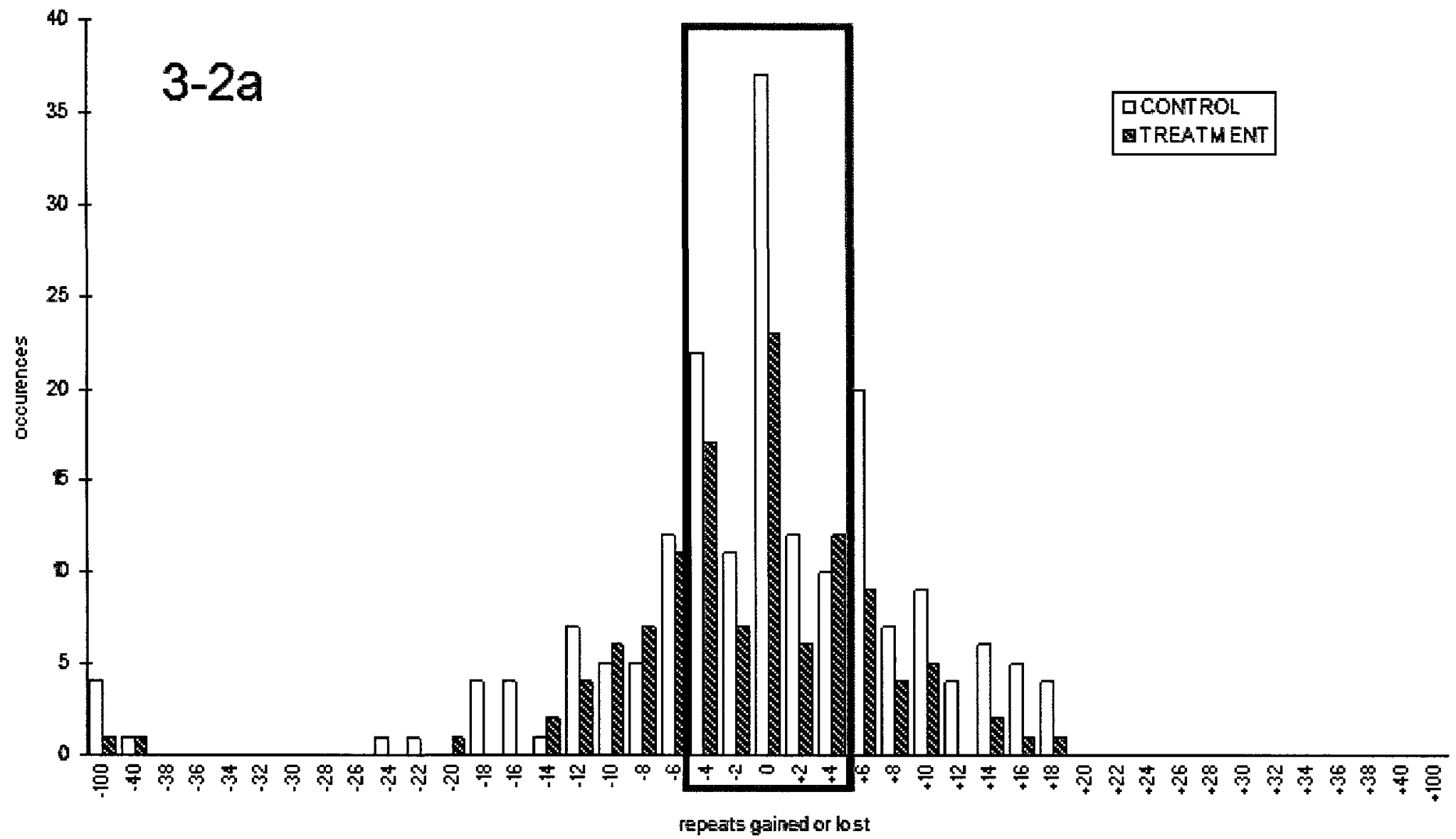




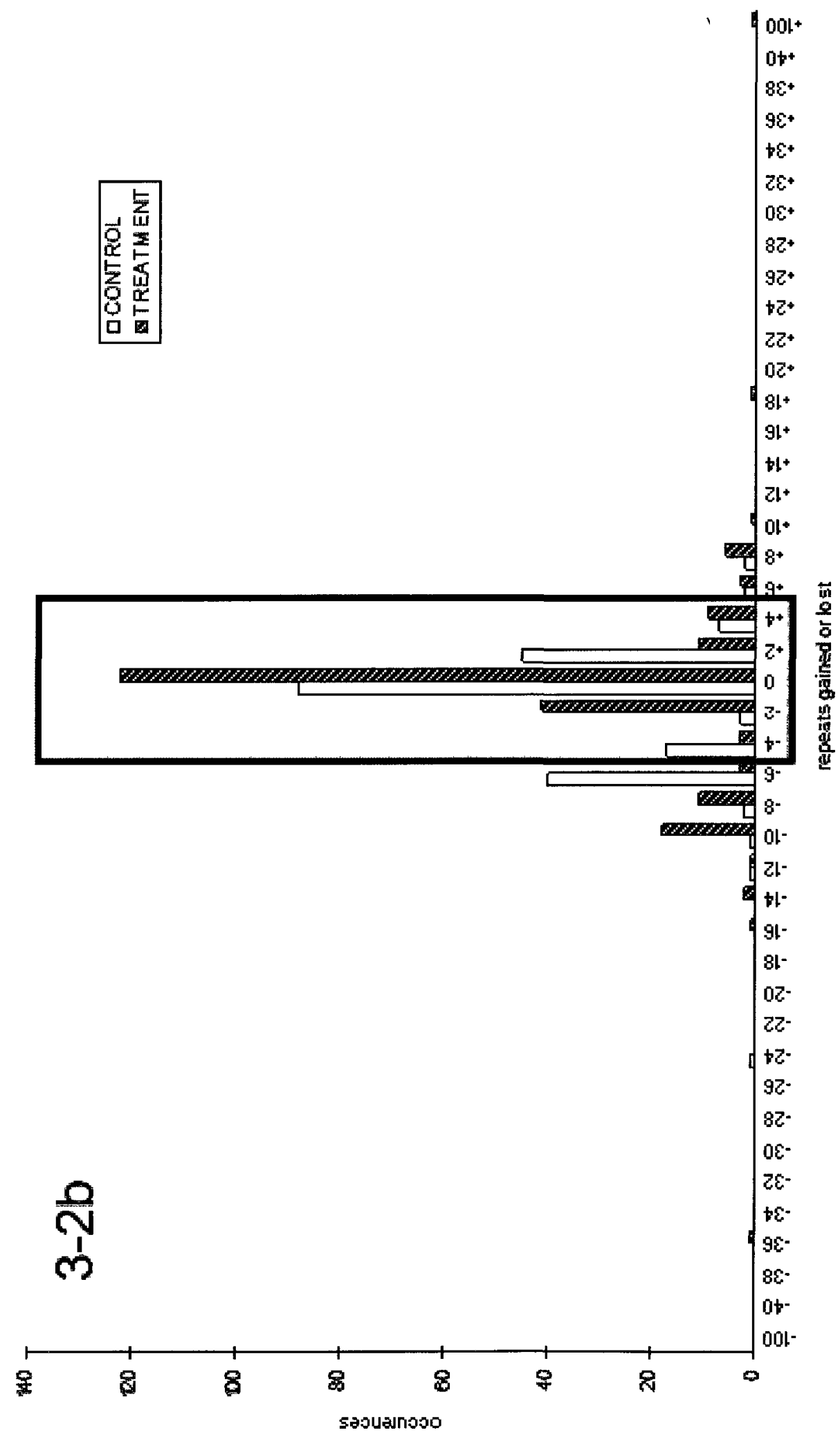


Table 3-1: Mutation Frequency of the F1 and F2 generation 
Table 3-1: Mutation Frequency of F1 and F2 generation

\begin{tabular}{|c|c|c|c|c|c|c|}
\hline $\begin{array}{c}\text { Generation/ } \\
\text { Allele Size }\end{array}$ & $\begin{array}{c}\text { Treatment } \\
\text { Group }\end{array}$ & $\begin{array}{c}\text { \# of } \\
\text { Progenitors } \\
\text { (95\% C.I.) }\end{array}$ & $\begin{array}{c}\text { \# of } \\
\text { Mutants }\end{array}$ & $\begin{array}{l}\text { Mutation } \\
\text { Frequency } \\
\text { (95\% C.I.) }\end{array}$ & $\begin{array}{c}\text { Fold } \\
\text { Increase }\end{array}$ & $\begin{array}{c}p- \\
\text { value* }\end{array}$ \\
\hline \multirow[t]{2}{*}{$\begin{array}{c}\text { F1 } \\
5.1 \mathrm{~Kb}\end{array}$} & Control & $\begin{array}{c}236 \\
(182,300)\end{array}$ & 8 & $\begin{array}{c}3.4 \% \\
(2.7 \%, 4.4 \%)\end{array}$ & \multirow[t]{2}{*}{1.12} & \multirow[t]{2}{*}{0.7} \\
\hline & DEP & $\begin{array}{c}129 \\
(102,170)\end{array}$ & 5 & $\begin{array}{c}3.8 \% \\
(2.9 \%, 4.9 \%)\end{array}$ & & \\
\hline \multirow[t]{2}{*}{$\begin{array}{c}\mathbf{F 2} \\
1.7 \mathrm{~Kb}\end{array}$} & Control & $\begin{array}{c}414 \\
(322,504)\end{array}$ & 18 & $\begin{array}{c}4.4 \% \\
(3.6 \%, 5.6 \%) \\
\end{array}$ & \multirow[t]{2}{*}{0.93} & \multirow[t]{2}{*}{0.7} \\
\hline & DEP & $\begin{array}{c}321 \\
(250,399) \\
\end{array}$ & 13 & $\begin{array}{c}4.1 \% \\
(3.3 \%, 5.2 \%) \\
\end{array}$ & & \\
\hline
\end{tabular}

* Score's test 
Table 3-2: Mutation analysis of gains versus losses 
Table 3-2:

\begin{tabular}{|c|c|c|c|}
\hline Analysis & $\begin{array}{c}\text { Degrees of } \\
\text { Freedom }\end{array}$ & Chi-Square value & Pr > Chi-Square* \\
\hline $\begin{array}{c}\text { Counts per bin is } \\
\text { equal }\end{array}$ & 42 & 74.87 & 0.0013 \\
\hline $\begin{array}{c}\text { Treatment effect for } \\
\text { individual bins }\end{array}$ & 42 & 23.28 & 0.9915 \\
\hline $\begin{array}{c}\text { Overall treatment } \\
\text { effect }\end{array}$ & 1 & 1.57 & 0.2098 \\
\hline
\end{tabular}

* Score's Test 


\subsection{Discussion:}

We examined the transmission of genetic instability to subsequent generations as a result of DEP exposure in utero. The study used SM-PCR to examine the mutation frequency at the $H M 1$ locus from F1 and F2 sperm DNA. The F1 analysis examined the $\mathrm{C} 57 \mathrm{Bl} / 6$ allele of the $\mathrm{F} 1$ generation. These animals were exposed in utero to DEP by maternal inhalation. Given the positive result in the pedigree analysis (Chapter 2), this analysis was intended as the positive control for the experiment. The F2 analysis measured mutation frequency of the CBA/J allele in the unexposed F2 generation sperm. The $\mathrm{CBA} / \mathrm{J}$ allele is derived from the control female mothers and would thus be indicative of untargeted effects occurring due to unexposed females being mated with exposed males. There was no significant increase in mutation frequency found for either the F1 or F2 generation.

SM-PCR analysis of the F1 C57B1/6 allele showed no increase in mutation frequency after DEP exposure in utero (Fig 1a). This result was unexpected, as pedigree data on these same mice showed a statistically significant increase in inherited mutations from the exposed males, and marginally significant increases in inherited mutations from the unexposed females when they were mated to exposed males [61]. The disagreement between these two results may be due to one of two possibilities, described below.

The lack of increased mutation frequency observed in the SM-PCR analysis of the F1 sperm, combined with the destabilization of the unexposed female allele [61], suggests that genetic instability occurs in embryogenesis of the F1 generation and leads to mutation in the F2 mice. This would not be caused by mutations in sperm, 
but by mutations arising in the early embryo. Such an effect may be mediated by an epigenetic signal. For instance, the in utero DEP exposure may cause the developing sperm to become epigenetically marked, possibly by methylation, but does not cause mutation directly in the sperm. The altered methylation might lead to genetic mutations after fertilization by an egg that, which could explain why we see an increase in mutation frequency in the pedigree analysis (done by comparing somatic DNA from F1 parents with that of F2 pups) [61] but not in the SM-PCR analysis. Changes in global methylation have been observed in the sperm of mature male mice following exposure to urban particulate air pollution [1]. In 2007, Liu et al. also observed both hyper and hypomethylation of different promoter regions after exposure to DEP [65]. Liu et al. also observed changes in gene expression after alterations in methylation occurred [65]. These studies indicate that environmental exposure has the ability to change the epigenome, and ultimately gene expression. Thus, it is possible that the lack of mutation measured in the sperm is the result of the transmission of an epigenetic signal, rather than transmission of mutations. However, other studies have shown similarities in sperm and pedigree mutation rates $[1,10-11$, $20,25,30-31,54,66]$. Thus, this possibility is not supported by the current literature.

The second and more likely explanation for the lack of induced mutations measured by SM-PCR may be technical differences between the two techniques. Our sperm analysis required the application of SM-PCR, whereas the pedigree approach uses restriction digests of genomic DNA and Southern blotting [7]. Because the $\mathrm{C} 57 \mathrm{Bl} / 6 \mathrm{HMI}$ locus is over $5 \mathrm{~Kb}$, it was very difficult to amplify. This led to a much smaller sample size than initially intended (actual F1 sample size $\sim 364$ molecules in 
total). This is substantially less than other SM-PCR experiments have used. For example, Yauk et al. used 458 (408, 523 (95\% confidence interval)) molecules for the control group alone, and $440(390,508$ (95\% confidence interval)) for the exposed group [54]. Thus, the present SM-PCR experiment used less than half the amount of molecules as compared to the Yauk et al. study [54]. Not only were there a low number of molecules, there were also fewer animals ( 3 exposed males and 4 control males). This may not represent the variability scored across the larger number of males analysed using the pedigree approach (6 families with exposed male parents, 9 families with control male parents) [61]. The small sample size may skew the results, and fail to attain statistical significance. Also, given that the large allele was so difficult to amplify, it indicates that the reaction may have been on the borderline of optimization for amplification. This could result in gain mutations being missed as they would be even larger and more difficult to amplify. Also due to their size, the $5.1 \mathrm{~Kb}$ bands are on the upper range of what can be scored, as only very large size changes are able to be detected reliably. SM-PCR has proven to be reliable in the past $[1,5,25,28,54,66]$; however, it is normally done with larger sample sizes and shorter alleles. For example, Yauk et al. used an allele $1.8 \mathrm{~kb}$ in size with approximately 700 molecules per treatment group, as opposed to our $5.1 \mathrm{~kb}$ region and $\sim 300$ molecules total [1]. Thus, the results and technical limitations suggest that the more likely explanation of the lack of effect in the F1 DEP exposed sperm was a combination of small sample size and amplification issues leading to an inability to find a statistically significant increase. Based on the pedigree results obtained (Chapter 2), technical and sample size limitations, and the knowledge that PAP in general has been shown to 
cause increased mutation in the sperm of adult males, an increase in mutations in sperm is expected to have occurred in the mice exposed in utero to DEP.

The F2 CBA/J allele showed no increase in mutation frequency after in utero DEP exposure of the F1 males (Fig 1b). The CBA/J allele reflects untargeted effects as it is the allele derived from unexposed females that were mated to exposed males. Any results observed here would have indicated a transgenerational persistent genetic instability. A number of outcomes were possible for the SM-PCR analysis of F1 and F2 sperm and can be used to support various models. First, increase in F2 mutation frequency would indicate that DEP exposure in utero results in persistent genetic instability in the offspring that can be passed on to the next generation. This was clearly not supported by our data. Lack of response in the F2 in the presence of mutations in the F1 sperm would indicate that the in utero DEP exposure resulted in induced mutations in the exposed animals only, and genetic instability was not transferable to the next generation. A third possibility would be that mutations only arise early in embryogenesis in the descendents of the exposed F1 generation. In the latter case, lack of mutation in the F1 sperm would be expected if the F2 generation develops mutations exclusively in early embryogenesis, but does not exhibit persistent instability at later stages. Because there was a statistically significant increase in mutation frequency of the exposed male allele, as well as a marginally significant increase in mutation frequency of the unexposed female allele using a pedigree analysis ([61], see chapter 2), the DEP exposure must have caused an increase in the exposed mutation frequency as well as genetic instability, not just an induced mutation. Thus, due to the lack of increase in mutation frequency observed in 
the F2 generation, the present data support the model that mutations arose early in embryogenesis, with no transmission of genetic instability. However, given the technical limitations of the SM-PCR on the F1, it is likely that mutations are also arising in the directly exposed allele.

Analysis of the mutation spectrum in the F1 germline (Fig 2a) showed no differences between the control and exposed animals. These findings suggest that if there are induced mutations in the exposed animals, the mechanisms of mutation are similar between induced and spontaneous mutation. This supports the indirect model for mutations described in Chapter 1, implicating an increase in mutation due to perturbations in the regular processes that contribute to spontaneous mutation (for e.g., polymerase errors), rather than a response to DNA damage or epigenetic changes at, or around, the locus. In addition, no differences were observed between the exposed and control mutation spectra obtained from the analysis of the F2 germline (Fig 2b), confirming the lack of effect of DEP on genetic instability. These results support the null hypothesis, that there was no persistent instability in the F2 generation as a result of DEP exposure.

Previous studies have shown transgenerational effects following exposure to radiation or ethylnitrosourea (ENU) $[6,8,31]$, and all, except one of these studies, were conducted on adult males. Thus, lack of transgenerational effects may be explained by differences in the chemicals or stage-specificity. However, Barber et al. exposed mice to radiation in utero on GD 12 and observed a transgenerational increase in ESTR mutation frequency [31]. Thus, in utero exposures are apparently capable of inducing these effects. 
Barber et al. hypothesized that transgenerational instability could be the result of changes in methylation status, of oxidative stress/inflammatory response, or arise from replication instability [6]. They suggested that the most likely explanation, based on their results, was replication instability. Barber et al. found higher rates of strand breaks in the unexposed generations of exposed adult males. These breaks were not the result of DNA repair deficiency (which is one hypothetical mechanism by which epigenetic changes may lead to transgenerational genetic instability)[6]. It was also observed that the unexposed generation did not have an increase in oxidative DNA damage, as would be expected with ROS damage caused from oxidative stress [6]. Thus, Barber et al. concluded that persistent DNA lesions, such as double strand or single strand breaks, were the cause of the instability in the unexposed generation [6]. It has previously been suggested that the mechanism of ESTR mutation is via replication slippage caused due to a pausing in DNA replication after an insult has incurred [27]. However, the exact mechanism in which the unexposed offspring inherit this damage is unclear. Dubrova et al. (2008) conducted an experiment using ENU instead of radiation to determine if a chemical mutagen that causes alkylation rather than strand breaks would still cause transgenerational instability [8]. ENU caused an increase in mutation frequency of the unexposed offspring, similar to results obtained using radiation [8]. Thus, it was concluded that the transgenerational genetic instability was the result of stress-like response to DNA damage [8].

Exposure to particulate air pollution has been shown to cause an increase in global DNA hypermethylation and increases in DNA double and single strand breaks in the sperm of adult males [1]. DEPs specifically, have been shown to cause an 
increase in oxidatively damaged DNA bases [42,50,67], DNA adducts [47], and increased strand breaks [44]. Thus it was anticipated that DEPs would also be capable of inducing transgenerational genetic instability. However, it is possible that the window of opportunity to induce transgenerational genetic instability was missed during this experiment. Perhaps there is only a small range of time, potentially during times of epigenetic changes, that is susceptible to mutagens. It is possible that this experiment missed that window of time, or perhaps the exposure was not high enough during that period. Dr. Dubrova has indicated that chronic low dose exposure to radiation did not induce a transgenerational effect, whereas acute exposure did (personal communication). Thus, it is possible that the dose of DEPs was simply too small to cause an effect. Perhaps a higher exposure, at the maximum tolerated dose, would show an effect.

Lastly, the mechanism through which DEPs cause an increase in mutation rates is unknown. It is possible that if the particles themselves are causing the mutagenic effect, they may not be able to cross the placenta to the developing fetus, unlike radiation, which can cause DNA damage in the fetus [68]. Studies have shown an increase in DNA adducts in the placenta of exposed fetuses [39], but not enough work has been completed on analysis of the fetal tissue.

\subsection{Conclusions and Future Work}

This work shows that exposure to $19 \mathrm{mg} / \mathrm{m}^{3} \mathrm{DEP}$ from GD 7 to 19 does not cause an increase in male germline mutation in the unexposed F2 generation. Dubrova et al. observed that transgenerational genetic instability is associated with 
many different forms of mutagen exposures [69]. The work from this laboratory suggests that there may be an increased, unprecedented risk to future generations of exposure to mutagens [69]. The same would be true of DEP if a transgenerational effect had been observed in the present study. Specifically, consideration would have to be given to the future generations of employees who work in and around DEP contaminated areas (e.g., traffic policeman, bus drivers, mechanics, etc.). The lack of response in the present study suggests that DEP exposure in utero would not contribute to persistent transgenerational genetic instability. However, more work is required in order to confirm this lack of response. This work should include examining DEP-exposed adult males to confirm that transgenerational genetic instability arises using an exposure time point that has been more frequently applied in this research field, and targeting additional stages of embryonic/fetal development. There are a number of improvements that could be implemented for future studies in this area. The first and most important would be to include a positive control in subsequent studies. Transgenerational effects have been observed following in utero exposure to $1 \mathrm{~Gy}$ acute radiation on GD 12 [31], therefore exposure to radiation on GD 12 would be an ideal positive control. Another improvement would be to analyze mouse strains with smaller alleles to remove confounding technical problems. Lastly, a larger sample size would increase the likelihood of achieving a statistically significant result. 


\subsection{Funding Source:}

This research was funded by grants from the Canadian Regulatory Systems for Biotechnology, Health Canada A-base funding and the Danish Research Council (grant 2052-03-0016), Air pollution in a life time health perspective (Airpolife).

Salary support for C.R. was provided by an Ontario Graduate Studies scholarship. 
Chapter 4:

Discussion 


\section{Chapter 4: Discussion}

This thesis investigated induced germline mutations and transgenerational genetic instability in mice exposed to DEPs in utero, and their unexposed offspring, respectively. Pedigree analysis showed that in utero exposure resulted in a statistically significant increase in germline mutation frequency of the exposed paternal allele and a marginally significant increase of the unexposed maternal allele [61] (Chapter 2). Maternal in utero exposure did not result in an increase in mutation frequency. This indicates that in utero exposure results in induced mutation and suggests potential non-targeted genetic instability of the unexposed maternal allele in early embryogenesis in the descendents of exposed males. SM-PCR analysis of the F1 and F2 germline did not demonstrate any increases in germline mutation frequencies (Chapter 3). The results do not support the ability of DEP exposures in utero to lead to persistent transgenerational genetic instability. However, more work is needed to confirm this negative result, including investigations following adult male exposures to determine if DEP can cause transgenerational genetic instability at all, and during different stages of gestation.

\subsection{Previous Experimental Results on the Animals from this Study:}

Tissues for the work conducted in this thesis were obtained from a behavioural study conducted by Hougaard et al. [35]. The aim of this study was to determine if in utero exposure to DEP had any effects on gestation, post-natal development, learning or memory. Their hypothesis was that in utero exposure to DEP would affect these outcomes due to previous studies that found that DEP may exhibit endocrine 
disrupting activity. To examine this hypothesis, the experimental design described in this thesis (i.e., pregnant C57B1/6 mice exposed to $19 \mathrm{mg} / \mathrm{m}^{3}$ Diesel Exhaust Particles (DEP) from gestational day 7 to 19 ) was used. No statistically significant effects were observed for cognitive abilities between the control and exposed groups. In addition, Hougaard et al. observed no statistical differences in gender ratios, time-to-delivery and litter size between the control and exposed groups, in either the F1 or F2 generation [35]. The only difference observed was in pup weight at birth and weight gain during lactation of the F1 generation [35]. The DEP exposed pups weighed less at birth, and gained weight more slowly, than their sham control counterparts [35]. The authors hypothesized that DEPs may be deposited in the lungs of the mothers, prolonging the period of exposure beyond the in utero period by potentially passing chemicals or signals through their milk. The weight difference did not persist into adulthood and adult F1 males from the control and exposed group had similar weights. The effects were also limited to the F1 generation, as no changes in any parameters were noted in the F2 [35]. Thus, the overall health of the pups was not highly compromised by the in utero exposure. However correlations have been shown between low birth weights and disease, such as coronary heart disease [70]. Hougaard et al. believe that exposure to DEP in utero causes reduced weight gain during lactation and that a change in the exposure method (e.g., fresh, whole exhaust as opposed to aged, resuspended DEP) may result in different, potentially more severe outcomes. The findings suggest that DEP exposure in utero had a potentially negative health effect on the F1 offspring, but that it did not extend to the F2 generation. 


\subsection{ESTR Mutation Analysis:}

The first goal of this thesis was to determine the effects of in utero exposure to particulate air pollutants on the developing germline of male and female pups. The pedigree demonstrated a statistically significant increase in paternal mutation frequency when the males were exposed to DEP in utero (2-fold increase, $p=0.047$ ) [61] (Chapter 2), as well as a marginally significant increase in the maternal allele mutation frequency when the males were exposed in utero ( 2 fold increase, $p=$ 0.074). These results suggest a non-targeted effect on the females after a male in utero exposure. The marginally significant results may have been due to a slightly smaller sample size in this group. In contrast to the results seen with the F1 males, there was no increase in mutation frequency at either allele after exposure of the females in utero [61]. The results support Hypothesis 1 of this thesis, that inhaled DEP results in germline mutation at ESTR loci in mice exposed during gametogenesis, and indicate that DEP exposure in utero results in germline mutation at ESTR loci in males.

The second goal of this thesis was to investigate the induction of potential transgenerational genetic instability in the F2. SM-PCR demonstrated no increase in germline mutation frequency of the F1 generation. This was unexpected given the pedigree results; however, this lack of increase, combined with the instability at the unexposed female allele measured in the pedigree study, could indicate the induction of mutation early in embryogenesis of the F2, rather than in the sperm of the F1. Alternatively, and more likely, technical issues associated with SM-PCR and a small samples size may have led to a negative result with sperm SM-PCR. SM-PCR 
analysis of the F2 generation also demonstrated no increase in germline mutation frequency. This analysis examined the maternally derived allele after a paternal in utero exposure. Thus, any effects seen here would have indicated true transgenerational effects. The results clearly demonstrate that exposure of pregnant dams to $19 \mathrm{mg} / \mathrm{m}^{3} \mathrm{DEP}$ from GD 7 to 19 did not cause transgenerational genetic instability in the descendents of F1 males (i.e., rejection of Hypothesis 2, that exposure to DEPs in utero will result in transgenerational genetic instability).

\subsection{Relevance:}

The results of this thesis suggest that the developing fetus is susceptible to the effects of DEPs and that some portion of DEPs may have the ability to cross the placenta. However, whether this effect is caused by the particles themselves, chemicals attached to them, metabolites of these chemicals, or an epigenetic signal remains to be clarified. Reliene et al. demonstrated very low levels of DNA adducts in embryonic tissue after exposure of up to $500 \mathrm{mg} / \mathrm{kg} /$ day DEP on embryonic day 10.5-15.5, with no increase in 8oxo-dG (a measure of oxidative stress)[59]. This suggests that PAHs that are adsorbed to DEP cross the placenta and affect the fetus. However, a later study in 2010 by Lee et al that used an environmental exposure of $\sim 107-155 \mu \mathrm{g} / \mathrm{m}^{3}$, demonstrated an increase in 8oxo-dG levels [67]. This indicates oxidative stress in the offspring, either due to the presence of chemicals or particles in the fetus, or inflammatory signalling cascades from the dams. More work, such as the fractionation of chemicals associated with the DEPs to investigate active components, is required in order to determine which portion of DEPs is mutagenic and the 
mechanism leading to mutation. Alternatively, fetal tissues could be studied to determine the presence or absence of DNA adducts or oxidative stress in the fetuses. These studies would advance our understanding of how DEPs cause mutation in male germ cells in utero.

DEPs were chosen as a model for PAP for several reasons. First, DEPs contribute to PAP in urban and industrial areas [37]. Second, Somers et al. determined that it was the particulate portion of air pollution that caused increases in mutation frequency [4]. Third, standard reference material was available for DEPs .These standards are well-characterized, stable and available for purchase. Thus, the use of a commercial reference material ensures reproducibility and facilitates comparison across studies. However, it is possible that a different particulate component of PAP, either natural or anthropogenic, is causing mutations as well, which may increase the mutation frequency synergistically. HEPA filters remove particles $0.3 \mu \mathrm{m}$ in diameter or larger, thus any particle in this size range is a possible contributor to mutagenicity. For example, mineral dust, a component of PAP, has been shown to induce inflammatory responses [71]. A correlation between inflammatory responses, oxidative stress and DNA damage has previously been established $[72,73]$. Thus, further work is needed to identify the specific components of PAP that lead to increased germline ESTR mutation.

The findings of this thesis are important for the general population, and in particular for pregnant women, who may be exposed to high levels of DEPs. For instance, the concentration of DEPs in urban centres varies between $17.8 \mu \mathrm{g} / \mathrm{m}^{3}$ and $116 \mu \mathrm{g} / \mathrm{m}^{3}$ [67], and US truck drivers are exposed to between 20 and $55 \mu \mathrm{g} / \mathrm{m}^{3}$ (for 
short and long haul drivers, respectively) [74]. However, the exposure in this study was $19 \mathrm{mg} / \mathrm{m}^{3}$. This is approximately equivalent to a human exposure of 2648.06 $\mathrm{mg} / \mathrm{m}^{3}$ (see calculation below). Given that this is orders of magnitude larger than an environmental dose, caution should be used when applying these results to the human population. However, large doses do give an indication of the potential effects and add knowledge to a field where information is still lacking.

Mouse: $\frac{19 \mathrm{mg} / \mathrm{m}^{3}}{\left(350 \mathrm{bpm}^{*}\right)(60 \mathrm{~min})(0.2 \mathrm{ml} / \mathrm{breath})}=$ Human: $\frac{\mathrm{X}}{(12 \mathrm{bpm})(60 \mathrm{~min})(813 \mathrm{ml} / \mathrm{breath})}$
$\mathrm{X}=$ Equivalent Human Exposure $=2648.06 \mathrm{mg} / \mathrm{m}^{3}$
*Breaths per minute

An alternative hypothesis is that the effects are not caused by the particles themselves or chemicals associated with these particles. Instead, these effects could be mediated by a signalling cascade (e.g., cytokines in the mothers that are upregulated in response to the particles, and trigger signalling cascades that affect the offspring) as discussed above. Hougaard et al. investigated the level of inflammation in the liver of pups via analysis of mRNA expression of inflammatory cytokines [35]. They determined that mRNA expression levels of inflammatory cytokines interleukin-6, monocyte chemoattractant protein 1 , and macrophage inflammatory protein-2 were slightly higher in DEP exposed pups, although not significantly so. The authors hypothesized that this could be caused by a tendency for increased 
inflammation in the liver of pups exposed to DEP in utero. More work is required to determine what precisely is crossing the placenta and making it to the developing fetus.

DEPs are generated from the exhaust of diesel engines. This exhaust is a complex mixture of different combustion products, the exact composition of which depends on the type of engine used, the engine load and the fuel used to run it. They are often associated with different Polycyclic Aromatic Hydrocarbons (PAHs) and nitrated PAHs [44]. Bulky DNA adducts, oxidative DNA damage and DNA strand breaks have all been detected after exposure to DEPs $[49,50,75]$. Diesel engines were commended for emitting lower levels of carbon monoxide (CO), carbon dioxide $\left(\mathrm{CO}_{2}\right)$ and hydrocarbons, but they actually generate up to 100 times more particles than petrol engines [37]. The effects of these particles are currently drawing more attention than in the past. This is because certain occupations are exposed to more DEPs than others. For instance, diesel engine emission testers are exposed to up to 107.25 $\mu \mathrm{g} / \mathrm{m}^{3}$ DEPs. It has also been demonstrated that bus drivers, who are exposed to DEPs on the job, have higher levels of oxidative stress on urban routes than rural routes, and after working days compared to days off [73]. The results of the Hougaard study and Chapter 2 of this thesis provide convincing evidence that in utero exposure to DEP has potentially detrimental effects on the developing fetus. If this is the case, it is worth evaluating the safety thresholds for exposures of pregnant women in these occupations. The results of Chapter 2 suggest that the male children of these women would be most at risk. However, caution should be advised when drawing conclusions based on these results. Lack of weight gain is certainly concerning, as it 
has known health associated outcomes, however, it is currently unclear what the health consequences are of increased tandem repeat mutation. This is the subject of intense research in other labs as connections have been made between tandemly repeated DNA sequences and human diseases and disorders [29]. Also, correlations between ESTR mutations and other endpoints, such as increased mutation at protein coding regions, has been established [6]. Thus, ESTR mutations are plausible markers for genetic instability caused by exposure.

Taken together, these results demonstrate that in utero exposure to DEP causes germline mutations, but not transgenerational genetic instability. Because this was a chronic dose that demonstrated germline effects, risk assessment should take future generations into account when considering regulatory endpoints.

\subsection{Future Directions/Recommendations:}

Several recommendations for additional work have been proposed as a result of this thesis. These recommendations range from increasing sample size to improving stage-specificity in the experimental design. These recommendations will be discussed in more detail below.

1- Studies conducted on radiation and ENU have shown that they cause increases in germline mutation frequency as well as transgenerational genetic instability. The present DEP study demonstrated the former but not the latter. Nothing was known about in utero exposure to DEP before this experiment; however, in order to investigate DEP further, another pedigree analysis should be undertaken. The 
sample size should be increased in order to confirm an increase in mutation frequency of the unexposed female allele, and to confirm that there is no effect after in utero exposure of females. Also, higher doses may make differences in mutation rates easier to observe between groups. Earlier gestational time periods of exposure should also be considered. Mitosis occurs continuously from Gestational Day (GD) 9-12 in both male and female developing germlines [14]. Female germ cells enter the first stage of Meiosis I on GD 13 and beyond this same day, mitosis events are rare in male germ cells. The exposure for this analysis was 1 hour a day from GD 7-19, however, ESTR mutation is understood to be a mitotic process and thus can only occur while cells are undergoing mitosis [25]. Given these parameters, the germ cells were only exposed for 5 days (GD 9-13) during which time ESTR mutations could have accumulated. Higher doses and a longer exposure period would ensure that all possible mitotic cells are exposed, even cells that happened to enter mitosis early or late, to a mutagenic dose of DEP.

2- One puzzling result in this thesis is the lack of increased mutation frequency following SM-PCR analysis of the F1 sperm. Additional SM-PCR analysis of sperm samples would shed light on the reasons for the observed discrepancies. The SM-PCR analysis would benefit from an increased sample size as well. Ideally, CBA/J mice would be exposed in utero and mated with $\mathrm{C} 57 \mathrm{Bl} / 6$ mice. This would ensure that the target allele is the shorter, easier to amplify allele in order to produce rapid and reliable PCR. If no increase in mutation frequency is observed, alternative hypotheses, such as changes in increased genetic instability in the early embryo 
mediated by an epigenetic mechanism should be examined in detail. For example, methylation status could be compared between exposed and control groups (either F1 sperm or F2 early embryos). These techniques would help determine if there is an epigenetic mechanism at work in the exposed animals.

3- A major recommendation for this study would be the inclusion of a positive control for induced germline mutation. Transgenerational effects have been seen following irradiation with 1 Gy of X-rays delivered on GD 12 [31]. Thus, a positive control would be pups exposed to $1 \mathrm{~Gy}$ of radiation on GD 12. A positive control would confirm whether or not the technique we applied in our lab was capable of measuring induced mutation.

4- SM-PCR is a remarkable test as it uses much fewer samples than traditional methods [13]. Furthermore, because somatic mosaic mutations can be more precisely quantified, SM-PCR offers a substantial improvement over the pedigree analysis. Barber et al. have estimated that an unrealistically high number of offspring from each male would need to be analyzed in order to unequivocally distinguish germline mosaicism in pedigree analysis (>90 offspring) [31]. In contrast, in an SM-PCR analysis, somatic mosaic mutations are easily discernible because the equivalent of $\sim 80$ offspring are scored per male. Moreover, it has been demonstrated that there is a high correlation between sperm and pedigree ESTR mutation rates [54]. Thus, if an ESTR mutation is observed in sperm, it is likely that the mutation will occur in the offspring of that sperm. Therefore, it is recommended that the most effective way to 
proceed is to minimize the number of pedigree studies that are conducted, because they can be influenced by mosaicisms. Instead, work should primarily be conducted with SM-PCR when possible.

5- Despite certain challenges, the application of SM-PCR to germ cell tandem repeat mutation analysis is an important mutagenicity assay. Spermatogenesis in mice and humans is quite similar [13]. Thus, mice are an excellent test model for human exposure in this respect. SM-PCR is a methodology that has worked well in our laboratory; however, it would be advisable to conduct additional experiments with increased doses and additional stages of gametogenesis to definitively conclude that there is no effect of DEPs on transgenerational genetic instability. There are many studies that indicate transgenerational genetic instability after exposures to adult males (using radiation, ENU, and different strains of mice $[6,8]$ ) but only one study currently exists that looks at transgenerational effects of exposure in utero [31]. Thus, in order to determine whether transgenerational genetic instability arises following exposure to DEP, it would be advisable to conduct a long-term chronic exposure to high doses of DEP in adult males (through to the F2 generation). This would be more aligned with previous work on transgenerational genetic instability.

6- The data in Chapter 2 indicate that DEP does affect the germline. More work should be carried out to determine if this effect can be reproduced using SMPCR. The results from Chapter 3 suggest that particles do not cause transgenerational effects, however it is possible that this study missed the appropriate exposure window 
in order to observe effects. Another possibility is that our exposure was not acute enough to cause a transgenerational effect. Dr. Dubrova has stated that low dose chronic exposures to radiation do not result in transgenerational genetic instability (personal communication), so it is possible that a higher dose of DEP, perhaps the maximum tolerable dose, is required to cause this effect.

7- Due to the limited window of time of female gametogenesis, very little is understood about mutagenic effects of exposure to toxicants during critical stages of female germline development. This is an important gap in knowledge that is in need of further data to evaluate potentially unknown human health effects. Therefore, additional work is required to determine the effects of exposure during critical stages of female gametogenesis. This should be accomplished using larger pedigree studies with specific in utero exposure periods. Also, these should be conducted using a standard mutagen (e.g., radiation, ENU, or Bleomycin) that is known to cause mutation during gametogenesis in order to precisely identify the window of sensitivity during oogenesis [76].

\subsection{Conclusions:}

This thesis demonstrates that DEP causes an increase in germline mutation in male mice following exposure in utero. It also indicates that this instability is transferred to the unexposed female allele indirectly. No transgenerational effects were seen. More work is required to determine if a particle exposure in utero will result in transgenerational genetic instability or what the particularly susceptible 
stages of female gametogenesis are. Furthermore, the health consequences of increased ESTR mutation are unknown. Additional experiments that address the biological importance of tandem repeat sequences (in the coding region of the genome, for instance) would be useful. 


\section{References}

[1] C. Yauk, A. Polyzos, A. Rowan-Carroll, C.M. Somers, R.W. Godschalk, F.J. Van Schooten, M.L. Berndt, I.F. Pogribny, I. Koturbash, A. Williams, G.R. Douglas, O. Kovalchuk. Germ-line mutations, DNA damage, and global hypermethylation in mice exposed to particulate air pollution in an urban/industrial location, Proc. Natl. Acad. Sci. U. S. A. 105 (2008) 605-610.

[2] C.L. Yauk, G.A. Fox, B.E. McCarry, J.S. Quinn. Induced minisatellite germline mutations in herring gulls (larus argentatus) living near steel mills, Mutat. Res. Fundam. Mol. Mech. Mutag. 452 (2000) 211-218.

[3] C.M. Somers, C.L. Yauk, P.A. White, C.L.J. Parfett, J.S. Quinn. Air pollution induces heritable DNA mutations, Proc. Natl. Acad. Sci. U. S. A. 99 (2002) 1590415907.

[4] C.M. Somers, B.E. McCarry, F. Malek, J.S. Quinn. Reduction of particulate air pollution lowers the risk of heritable mutations in mice, Science. 304 (2004) 10081010 .

[5] C.L. Yauk, L. Berndt, A. Williams, A. Rowan-Carroll, G.R. Douglas, M.R. Stampfli. Mainstream tobacco smoke causes paternal germ-line DNA mutation, Cancer Res. 67 (2007) 5103-5106.

[6] R.C. Barber, P. Hickenbotham, T. Hatch, D. Kelly, N. Topchiy, G.M. Almeida, G.D.D. Jones, G.E. Johnson, J.M. Parry, K. Rothkamm, Y.E. Dubrova. Radiationinduced transgenerational alterations in genome stability and DNA damage, Oncogene. 25 (2006) 7336-7342.

[7] Y.E. Dubrova, M. Plumb, J. Brown, J. Fennelly, P. Bois, D. Goodhead, A.J. Jeffreys. Stage specificity, dose response, and doubling dose for mouse minisatellite germ-line mutation induced by acute radiation, Proc. Natl. Acad. Sci. U. S. A. 95 (1998) 6251-6255.

[8] Y.E. Dubrova, P. Hickenbotham, C.D. Glen, K. Monger, H. Wong, R.C. Barber. Paternal exposure to ethylnitrosourea results in transgenerational genomic instability in mice, Environ. Mol. Mutagen. 49 (2008) 308-311.

[9] T.M. Singer, C.L. Yauk. Germ cell mutagens: Risk assessment challenges in the 21 st century, Environ. Mol. Mutagen. 51 (2010) 919-928.

[10] Y.E. Dubrova, A.J. Jeffreys, A.M. Malashenko. Mouse minisatellite mutations induced by ionizing-radiation, Nat. Genet. 5 (1993) 92-94. 
[11] C.L. Yauk, J.S. Quinn. Multilocus DNA fingerprinting reveals high rate of heritable genetic mutation in herring gulls nesting in an industrialized urban site (vol 93, pg 12137, 1996), Proc. Natl. Acad. Sci. U. S. A. 95 (1996) 15867-15867.

[12] International Agency for Research on Cancer (IARC). Special report: PolicyA review of human carcinogens - Part E: Tobacco, areca nut, alcohol, coal smoke, and salted fish, The Lancet. 10 (2009) 1033-1033-1034.

[13] T.M. Singer, I.B. Lambert, A. Williams, G.R. Douglas, C.L. Yauk. Detection of induced male germline mutation: Correlations and comparisons between traditional germline mutation assays, transgenic rodent assays and expanded simple tandem repeat instability assays, Mutat. Res. -Fundam. Mol. Mech. Mutag. 598 (2006) 164193.

[14] B. Mintz. Embryological phases of mammalian gametogenesis, Journal of Cellular and Comparative Physiology. 56 (1960) 31-47.

[15] J.C. Roach, G. Glusman, A.F.A. Smit, C.D. Huff, R. Hubley, P.T. Shannon, L. Rowen, K.P. Pant, N. Goodman, M. Bamshad, J. Shendure, R. Drmanac, L.B. Jorde, L. Hood, D.J. Galas. Analysis of genetic inheritance in a family quartet by wholegenome sequencing, Science. 328 (2010) 636-639.

[16] L.W. Russell. X-ray-induced mutations in mice, Cold Spring Harb Symp Quant Biol. 16 (1951) 327-327-336.

[17] S.S. Epstein. Use of the dominant-lethal test to detect genetic activity of environmental chemicals, Env. Health Persp. 6 (1973) 23-23-26.

[18] L. Machemer, D. Lorke. Dominant lethal test in mouse for mutagenic effects of saccharine, Humangenetik. 19 (1973) 193-198.

[19] P. Bennett. Microsatellites, J. Clin. Pathol. -Mol. Pathol. 53 (2000) 177-183.

[20] C.M. Somers. Expanded simple tandem repeat (ESTR) mutation induction in the male germline: Lessons learned from lab mice, Mutat. Res. -Fundam. Mol. Mech. Mutag. 598 (2006) 35-49.

[21] A. Jeffreys, R. Barber, P. Bois, J. Buard, Y.E. Dubrova, G. Grant, C.R.H. Hollies, C.A. May, R. Neumann, M. Panayi, A.E. Ritchie, A.C. Shone, E. Signer, J.D.H. Stead, K. Tamaki. Human minisatellites, repeat DNA instability and meiotic recombination, Electrophoresis. 20 (1999) 1665-1675.

[22] R. Kelly, G. Bulfield, A. Collick, M. Gibbs, A.J. Jeffreys. Characterization of a highly unstable mouse minisatellite locus - evidence for somatic mutation during early development, Genomics. 5 (1989) 844-856. 
[23] M. Gibbs, A. Collick, R.G. Kelly, A.J. Jeffreys. A tetranucleotide repeat mouse minisatellite displaying substantial somatic instability during early preimplantation development, Genomics. 17 (1993) 121-128.

[24] G. Wang, K.M. Vasquez. Non-B DNA structure-induced genetic instability, Mutat. Res. -Fundam. Mol. Mech. Mutag. 598 (2006) 103-119.

[25] C.L. Yauk. Advances in the application of germline tandem repeat instability for in situ monitoring, Mutat. Res. - Rev. Mut. Res. 566 (2004) 169-182.

[26] N.D. Allen, S.C. Barton, M.A.H. Surani, W. Reik. Mammalian development: A practical approach, 1987.

[27] R.C. Barber, L. Miccoli, P.P.W. Buul, K.L.A. Burr, A. van Duyn-Goedhart, J.F. Angulo, Y.E. Dubrova. Germline mutation rates at tandem repeat loci in DNA-repair deficient mice, Mut. Res. 554 (2004) 287-295.

[28] C.L. Yauk, A. Polyzos, A. Rowan-Carroll, I. Kortubash, A. Williams, O. Kovalchuk. Tandem repeat mutation, global DNA methylation, and regulation of DNA methyltransferases in cultured mouse embryonic fibroblast cells chronically exposed to chemicals with different modes of action, Environ. Mol. Mutagen. 49 (2008) 26-35.

[29] J.R. Gatchel, H.Y. Zoghbi. Diseases of unstable repeat expansion: Mechanisms and common principles, Nature Reviews Genetics. 6 (2005) 743-755.

[30] Y.E. Dubrova, M. Plumb, B. Gutierrez, E. Boulton, A.J. Jeffreys. Genome stability - transgenerational mutation by radiation, Nature. 405 (2000) 37-37.

[31] R.C. Barber, R.J. Hardwick, M.E. Shanks, C.D. Glen, S.K. Mughal, M. Voutounou, Y.E. Dubrova. The effects of in utero irradiation on mutation induction and transgenerational instability in mice, Mutat. Res. -Fundam. Mol. Mech. Mutag. 664 (2009) 6-12.

[32] W. Dean, D. Lucifero, F. Santos. DNA methylation in mammalian development and disease, Birth Defects Research Part C: Embryo Today: Reviews. 75 (2005) 9898-111.

[33] Envirotech International. Chapter 2: Air pollution, sources and characteristics, Malé Declaration on Control and Prevention of Air Pollution and its Likely Transboundary Effects for South Asia, 2004, pp. 9.

[34] A. Bassok, P.M. Hurvitz, C.C. Bae, T. Larson. Measuring neighbourhood air pollution: The case of seattle's international district, J. Environ. Plann. Manage. 53 (2010) 23-39. 
[35] K.S. Hougaard, K.A. Jensen, P. Nordly, C. Taxvig, U. Vogel, A.T. Saber, H. Wallin. Effects of prenatal exposure to diesel exhaust particles on postnatal development, behavior, genotoxicity and inflammation in mice, Particle and Fibre Toxicology. 5 (2008) 3.

[36] C.A. Pope, R.T. Burnett, M.J. Thun, E.E. Calle, D. Krewski, K. Ito, G.D. Thurston. Lung cancer, cardiopulmonary mortality, and long-term exposure to fine particulate air pollution, Jama-Journal of the American Medical Association. 287 (2002) 1132-1141.

[37] S. Salvi, A. Blomberg, B. Rudell, F. Kelly, T. Sandstrom, S.T. Holgate, A. Frew. Acute inflammatory responses in the airways and peripheral blood after short-term exposure to diesel exhaust in healthy human volunteers, American Journal of Respiratory and Critical Care Medicine. 159 (1999) 702-709.

[38] R.J. Sram, B. Binkova, P. Rossner, J. Rubes, J. Topinka, J. Dejmek. Adverse reproductive outcomes from exposure to environmental mutagens, Mutat. Res. Fundam. Mol. Mech. Mutag. 428 (1999) 203-215.

[39] C.E. Carlberg, L. Moller, P. Paakki, M. Kantola, H. Stockmann, R. Purkunen, P. Wagner, U. Lauper, M. Kaha, E. Elovaara, P. Kirkinen, M. Pasanen. DNA adducts in human placenta as biomarkers for environmental pollution, analysed by the P-32HPLC method, Biomarkers. 5 (2000) 182-191.

[40] H.R. Andersen, J.B. Nielsen, P. Grandjean. Toxicologic evidence of developmental neurotoxicity of environmental chemicals, Toxicology. 144 (2000) 121-127.

[41] National Institute of Standards and Technology. Certificate of analysis: Standard reference material 2975, Department of Commerce, United States of America. (2009) 1-1-10.

[42] L. Risom, M. Dybdahl, J. Bornholdt, U. Vogel, H. Wallin, P. Moller, S. Loft. Oxidative DNA damage and defence gene expression in the mouse lung after shortterm exposure to diesel exhaust particles by inhalation, Carcinogenesis. 24 (2003) $1847-1852$.

[43] N.R. Jacobsen, P. Moller, C.A. Cohn, S. Loft, U. Vogel, H. Wallin. Diesel exhaust particles are mutagenic in FE1-MutaMouse lung epithelial cells, Mutat. Res. 641 (2008) 54-54-57.

[44] A.K. Muller, E.O. Farombi, P. Moller, H.N. Autrup, U. Vogel, H. Wallin, L.O. Dragsted, S. Loft, M.L. Binderup. DNA damage in lung after oral exposure to diesel exhaust particles in big blue (R) rats, Mutat. Res. -Fundam. Mol. Mech. Mutag. 550 (2004) 123-132. 
[45] S.H. Ye, W. Zhou, J. Song, B.C. Peng, D. Yuan, Y.M. Lu, P.P. Qi. Toxicity and health effects of vehicle emissions in shanghai, Atmos. Environ. 34 (2000) 419-429.

[46] A.H. Hashimoto, K. Amanuma, K. Hiyoshi, Y. Sugawara, S. Goto, R. Yanogisawa, H. Takano, K. Masumura, T. Nohmi, Y. Aoki. Mutations in the lungs of gpt delta transgenic mice following inhalation of diesel exhaust, Environ. Mol. Mutagen. 48 (2007) 682-693.

[47] P.H. Danielsen, L. Risom, H. Wallin, H. Autrup, U. Vogel, S. Loft, P. Moller. DNA damage in rats after a single oral exposure to diesel exhaust particles, Mutat. Res. -Fundam. Mol. Mech. Mutag. 637 (2008) 49-55.

[48] K.E. Driscoll, J.M. Carter, B.W. Howard, D.G. Hassenbein, W. Pepelko, R.B. Baggs, G. Oberdorster. Pulmonary inflammatory, chemokine, and mutagenic responses in rats after subchronic inhalation of carbon black, Toxicol. Appl. Pharmacol. 136 (1996) 372-380.

[49] T. Ichinose, Y. Yajima, M. Nagashima, S. Takenoshita, Y. Nagamachi, M. Sagai. Lung carcinogenesis and formation of 8-hydroxy-deoxyguanosine in mice by diesel exhaust particles, Carcinogenesis. 18 (1997) 185-192.

[50] P. Moller, N.R. Jacobsen, J.K. Folkmann, P.H. Danielsen, L. Mikkelsen, J.G. Hemmingsen, L.K. Vesterdal, L. Forchhammer, H. Wallin, S. Loft. Role of oxidative damage in toxicity of particulates, Free Radic. Res. 44 (2010) 1-46.

[51] A.T. Saber, J. Bornholdt, M. Dybdahl, A.K. Sharma, S. Loft, U. Vogel, H. Wallin. Tumor necrosis factor is not required for particle-induced genotoxicity and pulmonary inflammation, Arch Toxicol. 79 (2005) 177-177-182.

[52] A.T. Saber, N.R. Jacobsen, J. Bornholdt, S.L. Kjaer, M. Dybdahl, L. Risom, S. Loft, U. Vogel, H. Wallin. Cytokine expression in mice exposed to diesel exhaust particles by inhalation. role of tumor necrosis factor, Part Fibre Toxicol. 3 (2006).

[53] M. Dybdahl, L. Risom, P. Moller, H. Autrup, H. Wallin, U. Vogel, J. Bornholdt, B. Daneshvar, L.O. Dragsted, A. Weimann, H.E. Poulsen, S. Loft. DNA adduct formation and oxidative stress in colon and liver of big blue (R) rats after dietary exposure to diesel particles, Carcinogenesis. 24 (2003) 1759-1759-1766.

[54] C.L. Yauk, Y.E. Dubrova, G.R. Grant, A.J. Jeffreys. A novel single molecule analysis of spontaneous and radiation-induced mutation at a mouse tandem repeat locus, Mutat. Res. -Fundam. Mol. Mech. Mutag. 500 (2002) 147-156.

[55] O. Niwa, R. Kominami. Untargeted mutation of the maternally derived mouse hypervariable minisatellite allele in F1 mice born to irradiated spermatozoa, Proc Natl Acad Sci U S A. 98 (2001) 1705-1705-1710. 
[56] R.J. Hardwick, M.V. Tretyakov, Y.E. Dubrova. Age-related accumulation of mutations supports a replication-dependent mechanism of spontaneous mutation at tandem repeat DNA loci in mice, Mol. Bio. Evo. 26 (2009) 2647-2647-2654.

[57] A. McLaren. Germ and somatic cell lineages in the developing gonad, Mol Cell Endocrinol. 163 (2000) 3-3-9.

[58] H.J. Badham, L.M. Winn. In utero exposure to benzene disrupts fetal hematopoietic progenitor cell growth via reactive oxygen species, Toxicol Sci. 113 207-207-215.

[59] R. Reliene, A. Hlavacova, B. Mahadevan, W.M. Baird, R.H. Schiestl. Diesel exhaust particles cause increased levels of DNA deletions after transplacental exposure in mice, Mutat. Res. -Fundam. Mol. Mech. Mutag. 570 (2005) 245-252.

[60] A. Luch, S. Amin, W.M. Baird, A. Beseratinia, K. El-Bayoumy, N.E. Geacintov, H. Glatt, A. Hirvonen, H. Naegeli, G.P. Pfeifer, D.H. Phillips, A. Seidel, P. Steinberg. The Carcinogenic Effects of Polycyclic Aromatic Hydrocarbons, 2005.

[61] C. Ritz, W. Ruminski, K.S. Hougaard, H. Wallin, U. Vogel, C.L. Yauk. Germline mutation rates in mice following in utero exposure to diesel exhaust particles by maternal inhalation, Mut. Res. 712 (2011) 55-55-58.

[62] O. Niwa. Induced genomic instability in irradiated germ cells and in the offspring; reconciling discrepancies among the human and animal studies, Oncogene. 22 (2003) 7078-7086.

[63] R.R. Sokal, F.J. Rohlf. Biometry, 1995.

[64] L. Sachs. Applied statistics, 1982.

[65] J. Liu, M. Ballaney, U. Al-Alem, C. Quan, X. Jin, F. Perera, L. Chen, R.L. Miller. Combined inhaled diesel exhaust particles and allergen exposure alter methylation of T helper genes and IgE production in vivo, Toxicol. Sci. 102 (2008) 76-81.

[66] C. Yauk, J.D.H. Stead. A review of tandem repeat sequences: Markers of genetic instability, 2010, pp. 151-151-167.

[67] M. Lee, M. Chen, S.C. Lung, C. Tsai, X. Yin, I. Mao. Exposure assessment of PM2.5 and urinary 8-OHdG for diesel exhaust emission inspector, Sci. Total Environ. 408 (2010) 505-510.

[68] H. Joshima. Decrease of erythropoiesis in the fetal liver of X-ray irradiated pregnant mice, J. Radiat. Res. 37 (1996) 177-184. 
[69] Y.E. Dubrova, P. Hickenbotham, C.D. Glen, K. Monger, H. Wong, R.C. Barber. Paternal exposure to ethylnitrosourea results in transgenerational genomic instability in mice, Environ. Mol. Mutagen. 49 (2008) 308-311.

[70] J.G. Eriksson, T. Forsen, J. Tuomilehto, C. Osmond, D.J.P. Barker. Early growth and coronary heart disease in later life: Longitudinal study, Br. Med. J. 322 (2001) 949-953.

[71] K. Donaldson, R.E. Bolton, D. Brown. Inflammatory cell recruitment as a measure of mineral dust toxicity, Ann. Occup. Hyg. (1988) 299-299-306.

[72] S. Loft, X.S. Deng, J.S. Tuo, A. Wellejus, M. Sorensen, H.E. Poulsen. Experimental study of oxidative DNA damage, Free Radic. Res. 29 (1998) 525-539.

[73] S. Loft, H.E. Poulsen, K. Vistisen, L.E. Knudsen. Increased urinary excretion of 8-oxo-2 '-deoxyguanosine, a biomarker of oxidative DNA damage, in urban bus drivers, Mutat. Res. -Genet. Toxicol. Environ. Mutag. 441 (1999) 11-19.

[74] M.E. Davis, T.J. Smith, F. Laden, J.E. Hart, A.P. Blicharz, P. Reaser, E. Garshick. Driver exposure to combustion particles in the U.S. trucking industry, J. Occup. Environ. Hyg. 4 (2007) 848-854.

[75] J.A. Bond, J.L. Mauderly, R.K. Wolff. Concentration-dependent and timedependent formation of dna adducts in lungs of rats exposed to diesel exhaust, Toxicology. 60 (1990) 127-135.

[76] P.D. Sudman, J.C. Rutledge, J.B. Bishop, W.M. Generoso. Bleomycin - femalespecific dominant lethal effects in mice, Mutat. Res. 296 (1992) 143-156. 